\title{
Expression of Distal-less, dachshund, and optomotor blind in Neanthes arenaceodentata (Annelida, Nereididae) does not support homology of appendage-forming mechanisms across the Bilateria
}

\author{
Christopher J. Winchell • Jonathan E. Valencia • \\ David K. Jacobs
}

Received: 26 July 2010 /Accepted: 9 November 2010 / Published online: 30 November 2010

(C) The Author(s) 2010. This article is published with open access at Springerlink.com

\begin{abstract}
The similarity in the genetic regulation of arthropod and vertebrate appendage formation has been interpreted as the product of a plesiomorphic gene network that was primitively involved in bilaterian appendage development and co-opted to build appendages (in modern phyla) that are not historically related as structures. Data from lophotrochozoans are needed to clarify the pervasiveness of plesiomorphic appendageforming mechanisms. We assayed the expression of three arthropod and vertebrate limb gene orthologs, Distal-less $(D l l)$, dachshund (dac), and optomotor blind (omb), in direct-developing juveniles of the polychaete Neanthes arenaceodentata. Parapodial Dll expression marks premorphogenetic notopodia and neuropodia, becoming restricted to the bases of notopodial cirri and to ventral portions of neuropodia. In outgrowing cephalic appendages, Dll activity is primarily restricted to proximal domains. Dll expression is also prominent in the brain. dac expression occurs in the brain, nerve cord ganglia, a pair of pharyngeal ganglia, presumed interneurons linking a pair of segmental nerves, and in newly differentiating
\end{abstract}

Communicated by D.A. Weisblat

C. J. Winchell $•$ D. K. Jacobs $(\bowtie)$

Department of Ecology and Evolutionary Biology,

University of California, Los Angeles,

621 Charles E. Young Drive South,

Los Angeles, CA 90095-1606, USA

e-mail: djacobs@ucla.edu

J. E. Valencia

Division of Biology, California Institute of Technology,

1200 East California Boulevard; MC 156-29,

Pasadena, CA 91125, USA mesoderm. Domains of omb expression include the brain, nerve cord ganglia, one pair of anterior cirri, presumed precursors of dorsal musculature, and the same pharyngeal ganglia and presumed interneurons that express dac. Contrary to their roles in outgrowing arthropod and vertebrate appendages, $D l l, d a c$, and $o m b$ lack comparable expression in Neanthes appendages, implying independent evolution of annelid appendage development. We infer that parapodia and arthropodia are not structurally or mechanistically homologous (but their primordia might be), that $D l l$ 's ancestral bilaterian function was in sensory and central nervous system differentiation, and that locomotory appendages possibly evolved from sensory outgrowths.

Keywords Polychaete $\cdot$ Appendages $\cdot$ Nervous system . Distal-less $\cdot$ dachshund $\cdot$ optomotor blind

\section{Introduction}

As specialized body outgrowths, appendages facilitate numerous processes basic to animal life such as sensing, feeding, locomotion, mating, and defense. One central question is which appendages among disparate animal taxa evolved from specific appendages of a common ancestor (classical homology) and which appendages arose as structural novelties (homoplasy)? Many appendage types are clearly apomorphic structures, so classical homology can be ruled out for certain comparisons. However, homology is an independent property of the various levels of biological organization (genes, developmental mechanisms, cell types, organs, etc.) (e.g., Abouheif 1997; 
Dickinson 1995; Minelli 1998; Striedter and Northcutt 1991), thus evoking further relevant questions: can homology be found by investigating mechanisms of appendage formation? What evolutionary inferences can be drawn from such investigations?

Comparative evidence from model experimental animals provides the initial answers to these questions. Drosophila appendages and vertebrate limbs share striking developmental-genetic similarities (reviews: Pueyo and Couso 2005; Shubin et al. 1997; Tabin et al. 1999). These observations (among others) led to the concept of "deep homology" (Shubin et al. 1997, 2009): historical continuity of developmental mechanisms in morphologically/ phylogenetically disparate structures. Given the lack of structural similarity between fly and vertebrate appendages and because phylogenetically intervening groups (e.g., protochordates) evidently never possessed appendages comparable to wings or limbs, Shubin et al. (1997) and Tabin et al. (1999) reasoned that fly and vertebrate appendages are not classical homologs. Instead they consider them "paralogs", novel appendages originating via the co-option of an ancient, conserved genetic network. Tabin et al. (1999) contended that this network evolved prior to the arthropod-tetrapod common ancestor and that it was used to build primitive appendages and has since been used to build appendage paralogs in arthropods, vertebrates, and possibly other bilaterian phyla. Shubin et al. (1997), Panganiban et al. (1997), Arthur et al. (1999), and Pueyo and Couso (2005) arrived at similar conclusions. Minelli (2000) proposed an alternative scenario: "axis paramorphism". Based on comparative morphology and a different set of developmental-genetic criteria, he posited an appendage-less ancestor and that appendages arose as homoplastic duplicates (paramorphs) of classical homologs, namely, the anteroposterior body axes of bilaterians.

Flies and vertebrates belong to two separate and major bilaterian clades: Ecdysozoa and Deuterostomia, respectively. These clades have been the primary subjects of appendage study to date. Comparatively little work has been done on the remaining major bilaterian clade, the Lophotrochozoa, which together with Ecdysozoa comprise the protostomes. To examine whether the deep homology of appendage-forming mechanisms is shared more broadly among bilaterians, developmental studies focusing on appendage genes must be extended to the Lophotrochozoa. In this study, three "appendage genes" (homologs of arthropod and vertebrate genes known to function in appendage morphogenesis) were isolated from the lophotrochozoan Neanthes arenaceodentata, an errant polychaete with an array of appendages, including locomotor/sensory segmental parapodia, which are added serially at a terminal growth zone and can thus be observed at multiple developmental stages in an individual. In the following paragraphs, we justify the selection of Distal-less, dachshund, and optomotor blind as genes of interest in the study of appendage evo-devo.

Distal-less $(D l l)$ is well known for its expression in the distal portions of developing annelid, arthropod, onychophoran, echinoderm, urochordate, and vertebrate appendages (Panganiban et al. 1997). Dll function has been examined in mice and several arthropods. In general, loss-of-function mutations or elimination of endogenous $D l l$ mRNA causes distal truncation or severe distal malformations in appendages (Angelini and Kaufman 2004; Cohen et al. 1989; Robledo et al. 2002; Schoppmeier and Damen 2001). Appendicular $\mathrm{Dll}$ expression has been documented in two polychaetes. In Chaetopterus variopedatus, it occurs mainly in antennae and throughout nascent parapodia (later in their distal tips) (Panganiban et al. 1997). In early trochophore larvae of the nereidid Platynereis dumerilii, it marks the lateral appendage (parapodial) fields (Denes et al. 2007; Saudemont et al. 2008), but expression has not been observed in later stages undergoing appendage outgrowth. Knowledge of $\mathrm{Dll}$ function combined with observations of its expression in diverse phyla has led to Dll's reputation as the chief regulator of distal morphogenesis in appendages. Assuming continuity of developmental processes, Dll expression in Neanthes is expected to occur in the distal portions of developing parapodia.

dachshund (dac) shows a conserved pattern of expression in the developing legs of broadly divergent arthropod taxa, for example: spider (Prpic et al. 2003), millipede (Prpic and Tautz 2003), isopod (Abzhanov and Kaufman 2000), branchiopod (Sewell et al. 2008), and insect (Inoue et al. 2002). This occurs in an intermediate domain along the proximodistal leg axis, between the proximal domain of extradenticle and homothorax coexpression and the distal domain of Dll expression. Together these genes are referred to as "leg gap genes"; they function antagonistically in a regulatory network to divide developing legs into three distinct units (Kojima 2004). The recent demonstration of arthropod-like gap gene expression in developing appendages of an onychophoran supports the homology of this network across panarthropods and indicates that it evolved to fulfill a role in appendage development unrelated to limb segmentation (Janssen et al. 2010). dac function has been analyzed with loss-of-function experiments in Drosophila (Mardon et al. 1994) and mRNA depletion in the hemipteran Oncopeltus (Angelini and Kaufman 2004). Both studies revealed mutant phenotypes in which intermediate leg segments were shortened and fused. Vertebrate dac homologs also control limb differentiation along the proximodistal axis. Dach1, for example, maintains the apical ectodermal ridge, an organizing center that drives limb outgrowth 
(Kida et al. 2004). This gene is also active in the broad mesodermal domains of the limb bud, and as development proceeds its expression becomes limited to the cartilage of emerging digits (Davis et al. 1999; Hammond et al. 1998; Horner et al. 2002). These data lead to an expectation of medial and/or distal expression of $d a c$ orthologs during Neanthes parapodial development.

optomotor blind (omb) belongs to the large family of Tbox transcription factors. It has an apparently conserved function across diverse arthropods in assigning dorsal fate to leg cells. In Drosophila, omb is expressed at high levels in imaginal disc cells that ultimately form the adult leg's dorsal surface (Brook and Cohen 1996). If omb is ectopically expressed in ventral cells, the adult leg shows dorsal-dorsal symmetry along its proximodistal axis (Brook and Cohen 1996; Maves and Schubiger 1998). Although functional studies of omb have not been done in other arthropods, embryonic expression patterns of omb homologs have been observed in three divergent spider species (Janssen et al. 2008) and a millipede (Prpic et al. 2005). The dorsal portions of all developing appendages (antennae, mouthparts, walking legs) expressed $o m b$; the same was true for the spiders' appendage derivatives (book lungs, tubular tracheae, spinnerets). The omb homologs of vertebrates are called $T b x 2$ and $T b \times 3$, and although they do not play a role in assigning dorsal fates, both are expressed in stripes along the anterior and posterior margins of embryonic limbs (Gibson-Brown et al. 1996). Furthermore, Tbx2 plays a crucial role in establishing the anteroposterior limb axis by tightly restricting Sonic hedgehog expression to only the posterior margin of the embryonic limb (Nissim et al. 2007). These data lead to the expectation, given continuity of appendage-patterning mechanisms, that omb expression during parapodial development should be dorsal if comparable to arthropods, or reflect a role in anteroposterior axial patterning if comparable to vertebrates.

We recently analyzed juvenile ontogeny and developing nervous system morphology in $N$. arenaceodentata (Winchell et al. 2010), a direct-developing nereidid. Here, we examine the expression of its $D l l, d a c$, and omb orthologs in several post-embryonic stages to assess whether lophotrochozoans share potentially homologous mechanisms of appendage development with ecdysozoans and/or deuterostomes.

\section{Materials and methods}

Animals

Maintenance of an $N$. arenaceodentata laboratory population and fixation/storage of juvenile worms was accomplished according to previously described methods (Winchell et al. 2010).
Gene isolation

Total RNA was extracted from juveniles of mixed age (3-17 segments) using a Qiagen RNeasy Kit ("Animal Tissues" protocol). cDNA was synthesized using the Superscript III First-Strand Synthesis System for RT-PCR (Invitrogen). Initial gene fragments were PCR-amplified using degenerate primers. The $D l l$ primers (forward: GTNAAYGGNAARGGNAARAARATG; reverse: AACCADATYTTNACYTGNGTYTG) targeted a 166-base pair (bp) fragment of the homeobox, the dac primers (forward: GGNGGNYTNCAYACNGTNTAYACNAA; reverse: CKYTTNGGNGGNCKNCCNGG) targeted a 206-bp fragment of Dac Domain 1, and the omb primers (forward: GARATGCCNAARMGNATGTAYAT; reverse: GCRAANGGRTTRTTRTCDATYTT) targeted a 313bp fragment of the T-box. The PCR strategy involved HotMaster Taq DNA Polymerase (5 Prime), $2 \mu \mathrm{L}$ of cDNA template, and a two-round process in which $1 \mu \mathrm{L}$ of the firstround product was used as template for the second round. The polymerase manufacturer's set-up protocol and cycling parameters were followed, except that both PCR rounds used two annealing temperatures: $42^{\circ} \mathrm{C}$ for the first five cycles and $48^{\circ} \mathrm{C}$ for the remaining 30 cycles. Fragments were excised from agarose gels, purified with an UltraClean 15 Kit (Mo Bio Laboratories), and cloned into pCR II-TOPO plasmids (Invitrogen). Plasmids were miniprepped using a Wizard Plus SV Minipreps Kit (Promega) and sequenced with an Applied Biosystems 3730 DNA Analyzer. Additional fragments, 5' and $3^{\prime}$ of the initial fragments, were obtained using the BD SMART RACE cDNA Amplification Kit (BD Biosciences Clontech). Composite consensus sequences of overlapping gene fragments were assembled with CodonCode Aligner. In an effort to screen for paralogous genes, the sequences of at least 12 positive clones were obtained for each of the gene fragments (i.e., initial, 5' RACE, and 3' RACE fragments).

Sequence alignments and phylogenetic analyses

BlastP (Altschul et al. 1997) was used to search GenBank for other metazoan proteins homologous to Dll, Dac, and Omb. In addition, Msh and BarH1 sequences, putative sister gene families to $\mathrm{Dll}$, were chosen as outgroups for the Dll analyses (Stock et al. 1996), and Ski/Sno/Corl homologs were employed as outgroups in the Dac analyses (Hammond et al. 1998; Kozmik et al. 1999; Takaesu et al. 2006). To our knowledge, relatives of the T-box family have not been identified. However, our phylogenetic analysis of the T-box family appears sufficient to determine subfamily affinity of the Neanthes omb-related gene. Initial amino acid alignments were made in ClustalX (Thompson et al. 1997) using default parameters. Manual editing of the alignments was done in MacClade (Maddison and Maddison 2005). Three search strategies were used to infer optimal gene trees: minimum 
evolution (ME), maximum likelihood (ML), and Bayesian inference (BI). For ME analyses, corrected distances were calculated with the Protdist program in PHYLIP (Felsenstein 2005) using default parameters, and subsequent searches were conducted with FastME (Desper and Gascuel 2002) using SPR post-processing. For non-parametric ME bootstrapping, 1,000 replicate datasets were generated with PHYLIP's Seqboot program and translated into distance matrices with Protdist. These matrices were analyzed with FastME, and a consensus tree showing nodal support values was generated with PHYLIP's Consense program. ProtTest (Abascal et al. 2005) was used to select the most appropriate model of protein evolution for each data set $(\mathrm{JTT}+\mathrm{I}+\mathrm{G}$ for the T-box alignment, JTT $+\mathrm{G}$ for the $d a c$ alignment, $\operatorname{RtRev}+\mathrm{G}$ for the Dll alignment). These models were implemented in PhyML (Guindon and Gascuel 2003) for ML searches and in MrBayes (Ronquist and Huelsenbeck 2003) for BI searches. The following PhyML options were used: empirical amino acid frequencies, 100 random starting trees, and SPR for tree topology search operations. ML bootstrapping in PhyML consisted of 100 replicates. The BI search included two independent runs, each for 1.5 million generations, sampled every 100 . Using the sumt command and setting burnin at 2001 , a $50 \%$ majority-rule consensus tree was computed from the remaining 13,000 samples of each run (26,000 samples total).

\section{Riboprobe synthesis}

Sense and antisense digoxigenin-labeled riboprobes were synthesized by in vitro transcription using SP6 and T7 MEGAscript kits (Ambion) and Dig-11-UTP (Roche Applied Science). The Dll riboprobe was 705 bases long, consisting of 194 bases of $5^{\prime}$ untranslated region (UTR) and 511 bases of predicted open reading frame (ORF), including the $5^{\prime}$ half of the homeobox. The dac riboprobe consisted of 1,237 bases of predicted ORF, including the last 181 bases of Dac Domain 1 and spanning 141 bases beyond Dac Domain 2. The omb riboprobe consisted of 765 bases of predicted ORF, including the first 358 bases of the T-box.

Whole-mount in situ hybridization

Stored specimens were rehydrated with 5 -min rinses in decreasing concentrations of methanol in phosphatebuffered saline plus $0.1 \%$ Tween 20 (PBTw): $75 \%, 50 \%$, $25 \%, 3 \times 100 \%$ PBTw. Proteinase K digestion $(20 \mu \mathrm{g} / \mathrm{mL}$ in PBTw) lasted $5 \mathrm{~min}$ for juveniles with up to four chaetigers, $8 \mathrm{~min}$ for five- to ten-chaetiger juveniles, and at least $12 \mathrm{~min}$ for all older juveniles. Proteinase activity was terminated with three rinses (two quick and one for $5 \mathrm{~min}$ ) in freshly prepared $2 \mathrm{mg} / \mathrm{mL}$ glycine in PBTw, followed by three more rinses in PBTw. Worms were then rinsed $3 \times$ $5 \mathrm{~min}$ in $0.1 \mathrm{M}$ triethanolamine (TEA; $\mathrm{pH} 7-8$ ), rinsed $2 \times$ $5 \mathrm{~min}$ in TEA without exchange but with each rinse receiving a fresh $0.3 \%$ volume of acetic anhydride, and washed for $3 \times 5 \mathrm{~min}$ in PBTw. Worms were then refixed with $4 \%$ formaldehyde in PBTw for $30 \mathrm{~min}$, followed by five 5-min washes in PBTw. Prehybridization occurred for $10 \mathrm{~min}$ in a $1: 1$ mixture of PBTw and $\mathrm{Hyb}(50 \%$ formamide, 5X SSC, 1X Denhardt's solution, $1 \mathrm{mg} / \mathrm{mL}$ CHAPS, $0.2 \mathrm{mg} / \mathrm{mL}$ yeast tRNA, $0.1 \mathrm{mg} / \mathrm{mL}$ heparin, and $0.1 \%$ Tween 20), $10 \mathrm{~min}$ in $100 \% \mathrm{Hyb}$, and $2 \mathrm{~h}$ in $\mathrm{Hyb}$ at $60^{\circ} \mathrm{C}$. For hybridization, worms were incubated at $60^{\circ} \mathrm{C}$ for $18 \mathrm{~h}$ in Hyb containing $1 \mathrm{ng} / \mu \mathrm{L}$ riboprobes. The latter were denatured at $80^{\circ} \mathrm{C}$ for 10 min prior to being added to the Hyb. Post-hybridization washes were in the following solutions (all at $60^{\circ} \mathrm{C}$; the first four were at $10 \mathrm{~min}$ each): $100 \% \mathrm{Hyb}, 3: 1 \mathrm{Hyb}$ and SSC-CH (2X SSC $+3 \mathrm{mg} / \mathrm{mL}$ CHAPS), 1:1 Hyb and SSC-CH, 1:3 Hyb and SSC-CH, SSC-CH $(3 \times 20 \mathrm{~min})$, and finally $0.2 \mathrm{X} \mathrm{SSC}+3 \mathrm{mg} / \mathrm{mL}$ CHAPS $(3 \times 20 \mathrm{~min})$. Following three 5 -min rinses in PBTw at room temperature, worms were incubated in blocking solution (10\% normal sheep serum in PBTw) for $1-3 \mathrm{~h}$. Worms were then exposed to anti-digoxigenin-AP Fab fragments (Roche Applied Science) at a 1:2,000 dilution in blocking solution (these antibodies were first preabsorbed with finely chopped Neanthes adults for $24 \mathrm{~h}$ at $4^{\circ} \mathrm{C}$ in PBTw). Post-antibody washes were done at room temperature in PBTw for $5 \mathrm{~h}$, changing the solution at least once per hour. Worms were then rinsed $3 \times 5 \mathrm{~min}$ in fresh alkaline phosphatase (AP) buffer (100 mM Tris, pH 9.5; $100 \mathrm{mM}$ $\mathrm{NaCl} ; 50 \mathrm{mM} \mathrm{MgCl}_{2} ; 1 \mathrm{mM}$ levamisole; $0.1 \%$ Tween 20 ). The color reaction developed in AP buffer plus $4.5 \mu \mathrm{L} / \mathrm{mL}$ NBT and $3.5 \mu \mathrm{L} / \mathrm{mL}$ BCIP (Roche Applied Science). Reactions were stopped after $15 \mathrm{~h}$ to 3 days with $3 \times$ 5 min rinses in PBTw, followed by at least $1 \mathrm{~h}$ of rinsing. Worms were then dehydrated in a methanol series and stored at $-20^{\circ} \mathrm{C}$ in $100 \%$ methanol for at least 2 days; this had the effect of removing some of the background staining.

\section{Photomicroscopy and histology}

For whole-mount imaging of gene expression, specimens were rehydrated in a PBTw series and then dehydrated in increasing concentrations of glycerol in PBTw (in 10\% increments from $10 \%$ to $80 \%$ ). They were cleared for at least 2 days in $80 \%$ glycerol before mounting. For a more thorough analysis of gene expression, some specimens were sectioned transversely prior to being photographed. They were first embedded in Poly/Bed 812-BDMA (Polysciences), following the manufacturer's protocol. Sectioning was done at a thickness of $5 \mu \mathrm{M}$ using a Histo diamond knife (Diatome) and an LKB ultramicrotome. Sections were 
mounted under coverslips with Clarion mounting medium (Biomeda). The Nar-dac-probed specimens chosen for sectioning were counterstained prior to embedding with Nuclear Fast Red and Light Green counterstains (Biomeda). Specimens and sections were analyzed with a Leica DMR microscope using Nomarski or bright field illumination and photographed with a Nikon Coolpix 4300 digital camera. Image brightness and contrast were adjusted with Adobe Photoshop software.

\section{Results}

Identification of Neanthes Dll-, dac-, and omb-related genes

The Dll-related composite sequence from Neanthes (GenBank accession number FJ164112) is 2,548 bp in length, containing $194 \mathrm{bp}$ of 5' UTR (with one in-frame stop codon), a 1,053 bp ORF, and a 1,301 bp 3' UTR. It was built from a sequencing survey of 40 positively identified $\mathrm{Dll}$ clones; no paralogous copies were found. ME analysis of the Dll data set (60 amino acid positions representing the Dll homeodomain) yielded a tree (Fig. 1a) in which the Neanthes sequence groups with that of Platynereis with significant bootstrap support (84\%). Few other nodes on the tree show significant support, which we judge to be ML and ME bootstrap percentages in the range of $\sim 70$ to 100 and BI posterior probabilities $\geq 95$. The low nodal support is likely due in large part to the paucity of alignable sites among Dll proteins of divergent species and to longbranch attraction artifacts. The latter notion stems from the observed basal ingroup positions of the long nematode Dll and human Dlx3 branches in the ME tree (Fig. 1a) and from the ML tree's aberrant topology (not shown), which displayed a nematode Dll+BarH1 outgroup pairing and basal positioning for the invertebrate chordate sequences (not shown, but note the tunicate's long branch in Fig. 1a). Despite these difficulties, the short Neanthes branch nests within known Dll sequences, separate from Dll's Msh+BarH1 sister group (Stock et al. 1996), indicating Dll orthology. We therefore refer to this sequence as Nar-Dll.

The Neanthes dac-related composite sequence (GenBank accession number FJ164113) represents only the initial dac fragment and the dac 3' RACE fragment. 5' RACE PCR efforts yielded no fragments whose sequence overlapped with the initial or 3' RACE fragments. This sequence was built from 33 positively identified dac clones, none of which showed evidence of paralogy. It is 3,548 bp in length, containing $1,390 \mathrm{bp}$ of ORF and a 2,155-bp 3' UTR. The ORF includes more than half the $5^{\prime}$ dac box, which encodes Dac Domain 1 (DD1), and the entire $3^{\prime}$ dac box, which encodes Dac Domain 2 (DD2). The Dac alignment included 205 amino acid positions representing the full lengths of DD1 and DD2, although one third of the sequences were incomplete. The ML, BI, and ME analyses of this data set incorrectly rooted the Dachshund ingroup within the vertebrate sequences (ML tree: Fig. 1b). This spurious result is most likely due to the insufficient similarity between the Dac ingroup proteins and their putatively closest outgroup, Ski/Sno/Corl proteins (Hammond et al. 1998; Kozmik et al. 1999; Takaesu et al. 2006). The alignment of these proteins is limited to the $\sim 100$-amino acid DD1/Ski/Sno/Corl domain, which shows $<30 \%$ sequence identity between the ingroup and outgroup. Phylogenetically appropriate rooting of the Dac ingroup at the internode between chordates and protosomes yields a split between these groups that is significantly supported by BI $(98 \%$; Fig. 1b). With this rooting, the lancelet is sister to a well-supported vertebrate clade ( $>95 \%$ for all three methods), and Neanthes is sister to a well-supported Arthropoda ( $>95 \%$ for ML and BI, $83 \%$ for ME). Given that the Neanthes branch is not long and falls in its phylogenetically expected location (as sister to arthropods), we infer dac orthology and refer to this sequence as Nar-dac.

The omb-related composite sequence (GenBank accession number FJ164114), built from 42 positively identified omb clones, is 2,564-bp long and contains 1,460 bp of ORF and a 1,104-bp 3' UTR. Because the 5' RACE sequence did not contain an in-frame stop codon, it is assumed that the entire ORF was not recovered. A phylogenetic analysis of five or more phylogenetically divergent sequences from each of the eight T-box subfamilies was undertaken to assess the orthology of our Neanthes sequence. The analysis included 177 amino acids, which encompass the entire T-domain except $\sim 13$ sites in the central portion that were unalignable across the subfamilies. The T-box gene tree (Fig. 1c) shows strong support for the monophyly of each T-box subfamily except Tbx6. Barring an unlikely root position, the Neanthes sequence is placed within a robust $\mathrm{Tb} 2 / 3$ subfamily, which received $97 \% \mathrm{ML}$ and $99 \%$ ME bootstrap support and 100\% BI support. The Neanthes omb-related gene is clearly an omb ortholog and is named Nar-omb.

\section{Expression of Nar-Dll}

Nar-Dll expression associates with all developing appendages and the brain. Components of these broad expression domains persist and can be traced from hatchlings through the eight-chaetiger stage (the latest stage examined). Below, we first describe the expression in appendages, followed by observations of brain expression.

At the hatchling stage, Nar-Dll expression in the developing palps and anterior cirri appears ring-like (Fig. 2a), and parapodial expression occurs as distinct patches separately marking the dorsal and ventral divisions (notopodia and neuropodia, respectively) (Fig. 2b). A closer ventral view of the posterior end (Fig. 2c) reveals $\mathrm{Nar}-\mathrm{Dll}$ expression throughout the developing anal cirri (albeit very 
faint) and in the most lateral ectodermal regions, which correspond to the nascent parapodia.

By the four-chaetiger stage, cephalic appendages and several pairs of anterior parapodia have undergone modest outgrowth. In most cases, Nar-Dll transcripts are notably absent from their distal tips; instead they accumulate near the bases of the antennae (Fig. 2e, late three-chaetiger stage) and in basal ring-like patterns around the developing palps, anterior cirri, and dorsal (notopodial) cirri (Fig. 2g, j). Faint patch-like Nar-Dll expression occurs in the neuropodia, primarily along their ventral surfaces, and is most intense at the proximal bases of more mature parapodia (Fig. 2i; 21 for a five-chaetiger juvenile). The latter, darker patterns, appearing just ventromedial to the neuropodial cirri, partially overlap with the locations of developing parapodial ganglia (Winchell et al. 2010) and thus probably represent cells of the peripheral nervous system (PNS). As was the case for hatchlings, Nar-Dll expression in the most nascent segments of four-chaetiger juveniles is exclusively ectodermal, occurring laterally in pre-morphogenetic parapodia (Fig. 2h).

The preceding patterns are similar in the later stages examined (late five- and eight-chaetiger juveniles). In short, parapodial expression patterns include rings circumscribing the bases of the dorsal cirri (Fig. 2k, 1, t) and patches restricted primarily to ventral portions of the neuropodia but excluding the ventral cirri (Fig. 2k, 1, r, s) (although expression in some nascent neuropodia was ring-like). Cells expressing $\mathrm{Nar}-\mathrm{Dll}$ in the presumed parapodial ganglia (i.e., the medial-most extent of expression on the ventral side of the worm; arrowheads in Fig. 2r) are separated by a cleft showing no staining. This blank space possibly represents the axonal tracts of the large parapodial (i.e., second segmental) nerve passing through each ganglion (Winchell et al. 2010). Continued Nar-Dll expression occurs near the bases of these other appendages: antennae (albeit faint and not in a continuous ring; Fig. 2o), anterior cirri (Fig. 2p, q), anal cirri (Fig. 2r, s), and palps. In the latter, however, expression was quasi-circumferential and occurred halfway along the proximodistal axis (near the articulation between the proximal palpophores and distal palpostyles) (Fig. 2q).

In the stages examined here, Nar-Dll transcripts in the CNS are restricted to the brain; no detectable expression occurs in the ventral nerve cords (VNC). Nar-Dll's activity is widely present in the hatchling brain (Fig. 2a, bracketed), most prominently in a bilateral pair of cell clusters dorsal and slightly lateral to the developing palps. At the late three-chaetiger stage, Nar-Dll expression in the brain occurs conspicuously in three bilateral pairs of cell clusters. First, the small "posterior clusters" reside near the posterior margin of the brain, dorsal to the pharynx (Fig. 2d). Second, the larger "middle clusters" (Fig. 2e), which are deep, lateral, and slightly anterior to the "posterior
Fig. 1 Gene trees for the new N. arenaceodentata sequences and related sequences from GenBank, constructed from deduced amino acid sequences using minimum evolution (a) or maximum likelihood and the best-fit model of protein evolution for the respective data set $(\mathbf{b}, \mathbf{c})$. Different measures of nodal support are shown; from top to bottom or left to right, these are: maximum likelihood bootstrap score, Bayesian inference posterior probability and minimum evolution bootstrap score. Asterisks indicate nodes for which all three support values are $\geq 95$. Support values under 50 are not shown. Branch lengths are proportional to molecular change (amino acid substitutions/site) between nodes; see scale bars for measurement. The length of interrupted branches was halved to improve the figure's presentation. The scientific names for the terminal taxa are as follows: acorn worm 1 Saccoglossus kowalevskii, acorn worm 2 Ptychodera flava, aphid Acyrthosiphon pisum, beetle Tribolium castaneum, brine shrimp A. franciscana, butterfly Bicyclus anynana, chicken Gallus gallus, chimp Pan troglodytes, ctenophore Pleurobrachia pileus, fly Drosophila melanogaster, frog 1 Xenopus tropicalis, frog 2 Xenopus laevis, honey bee Apis mellifera, human Homo sapiens, jellyfish Podocoryne carnea, lamprey Petromyzon marinus, lancelet 1 Branchiostoma floridae, lancelet 2 Branchiostoma belcheri, limpet Patella vulgata, milkweed bug Oncopeltus fasciatus, millipede Glomeris marginata, mouse Mus musculus, mysid shrimp Americamysis bahia, nematode $C$. elegans, polychaete $P$. dumerilii, salamander Ambystoma mexicanum, sea anemone Nematostella vectensis, sea urchin Strongylocentrotus purpuratus, shark Triakis semifasciata, spider 1 Cupiennius salei, spider 2 Steatoda triangulosa, spider 3 Achaearanea tepidariorum, sponge Sycon raphanus, tadpole shrimp Triops longicaudatus, tunicate C. intestinalis, woodlouse Porcellio scaber, Zebrafish Danio rerio. a Gene tree for sequences related to Drosophila Distal-less, rooted with $\mathrm{msh}$ and BarH1 homologs. GenBank accession numbers for the analyzed sequences, in order from top to bottom of the tree, are: BAG49469, AAL69325, AAG39634, ABN49265, CAC34380, AAP79300, BAA89014, ACN66454, CAJ38799, P53772, NP_001027820, NP_001123282, AAV85986, AAG41498, NP_571380, NP_001093727, NP_001074359, XP_001638618, NP_005211, Q18273, NP_001158403, CAJ38810, NP 523387, NP_031552. b Gene tree for sequences related to Drosophila dachshund, rooted with Ski and Sno homologs. GenBank accession numbers for the analyzed sequences, in order from top to bottom of the tree, are: XP_394482, AAS93632, AAC46506, XP 001945046, XP 969771, AB̈E68634, ABE68636, AAK58707, ABE68635, AAK58706, CAD57736, CAD82906, ACN66455, AAQ11368, NP 001072176, AAL76234, CAA06665, AAH21219, AAI62622, NP 694487, NP 694488, CAI42588, NP_001103515, AAF22354, ACZ95098, NP 001103213, ABJ09066, NP 990505. c Unrooted tree for the Tbox family of transcription factors. GenBank accession numbers for the analyzed sequences, in order from top to bottom of the tree, are: BAA37091, NP 033335, CAD12821, P55965, CAD21521, CAC19335, AAU95752, NP_033348, NP_001081810, NP_037483, BAB19985, BAB63370, NP_001034280, NP_001027752, NP 648282, NP 571127, BAC $20262, \mathrm{P} 70327$, ACN66456, AAA 28736 , ABD97269, NP 932169, NP 001081374, AAG34888, NP 498088, CAE45769, NP 989437, NP 058650, EDL26527, NP 705950, AAG34891, CAA67304, BAD 16721, EAW94048, NP 571581, NP 001027590, ABM91947, NP 001030290, AAG34887, BAD16723, CAA76529, ABV54787, EDL19781, NP_001025708, ABU50779, CAE45765

clusters", correspond to the prominent Nar-Dll-expressing clusters noted for the hatchling brain. Third, the "anterior clusters" are immediately in front of the ventral portion of the brain's neuropil (Fig. 2f). From the anteromedial edge of this neuropil, arcs of cells expressing $\mathrm{Nar}-\mathrm{Dll}$ extend to 

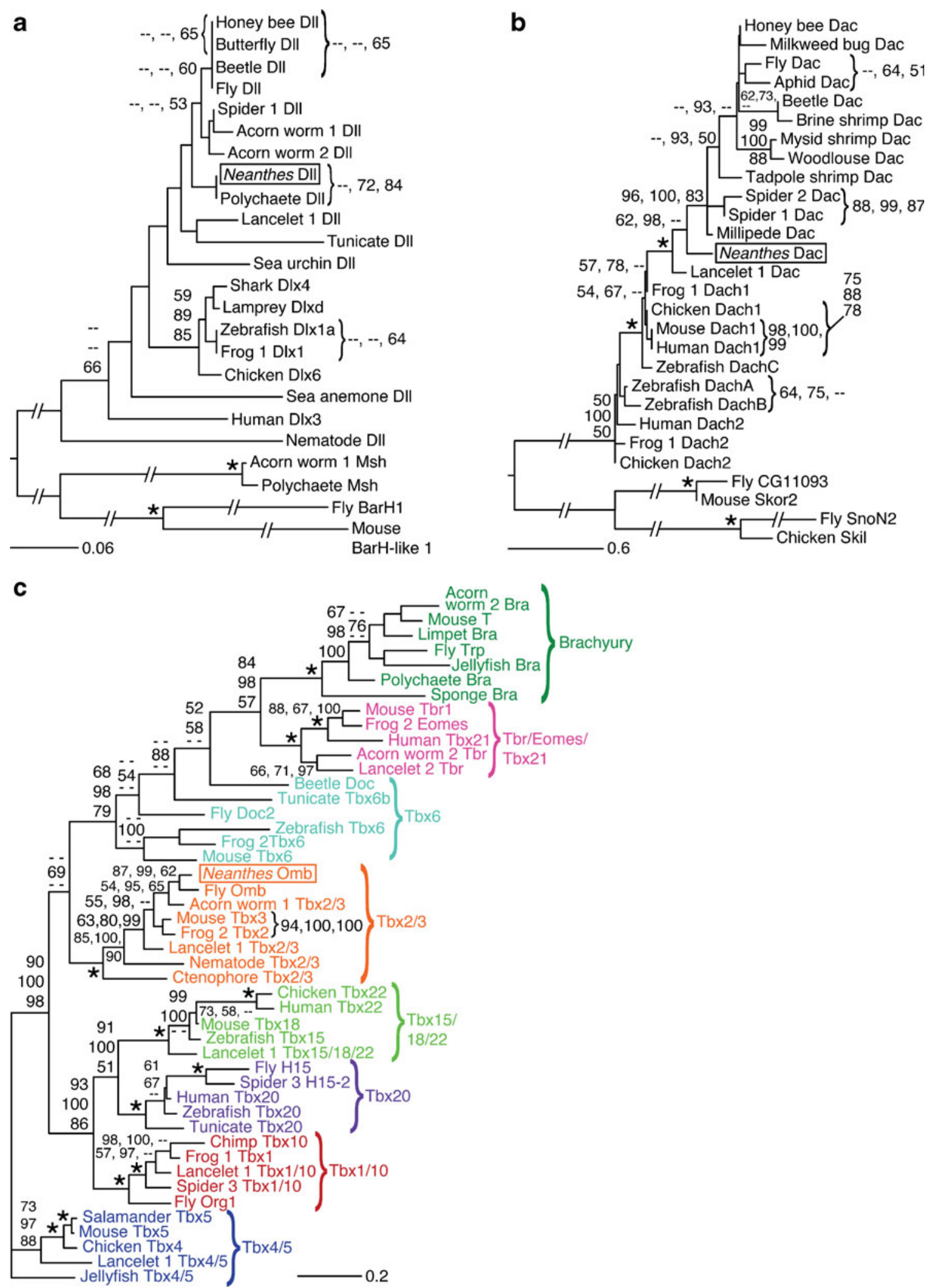

the anterior terminus of the prostomium (medial to the antennae), and a small patch of Nar-Dll-expressing cells occurs between these arcs on the midline of the prostomium (Fig. 2f). By the eight-chaetiger stage, the cells forming these arcs and the medial patch have ceased their expression, but expression in the posterior prostomium expands, occurring in scattered groups of cells (between and behind the posterior pair of eyes; Fig. 2n) that 
apparently reside in ganglia of the brain's posterodorsal cortex (Winchell et al. 2010). The "middle clusters" continued expressing $\mathrm{Nar}-\mathrm{Dll}$ in eight-chaetiger juveniles (Fig. 20). A transverse section through this level of the prostomium reveals that these cells lie at the sides of the brain just below the anterior pair of eyes (Fig. 2m), presumably where the nascent Holmgren's cerebral commissural ganglia lie (Winchell et al. 2010). Finally, Nar-Dll shows persistent expression in the "anterior clusters" (Fig. 2p). The identity of these cells is uncertain, but they lie near the "lateral common roots", extensions of neuropil that receive, for example, nerves of the palps, Langdon's organs, and corpora pedunculata (Winchell et al. 2010).

\section{Expression of Nar-dac}

Overall, Nar-dac transcripts are broadly present in the central nervous system - especially in the VNC - and in relatively limited domains within the PNS and mesodermal tissue. No patterns were observed that would indicate a role for this gene in appendage morphogenesis. In hatchlings, Nar-dac expression is present in the pygidium and in small bilateral mesodermal regions immediately in front of the pygidium (Fig. 3a). The pygidial expression ceases beyond the hatchling stage, but the mesodermal staining, occurring in the most posterior (newly differentiated) mesodermal tissue, persists through the 12-chaetiger stage (the latest stage examined) but data are shown only through the four-chaetiger stage (Fig. 3f, h). Expression in the hatchling CNS encompasses many cells within the nerve cord and brain (Fig. 3a, b), including small cell clusters located in the dorsolateral corners of the prostomium, which appear to be isolated from the brain's main mass (Fig. 3b). Based on their position, these cells are interpreted as belonging to the posterodorsal-most pair of brain ganglia (PDBG) (see Winchell et al. 2010).

At the mid three-chaetiger stage, after the prostomium has substantially proliferated outward from the yolk, it becomes easier to discern the relative positions of Nar-dacexpressing cells in the juvenile head (Fig. 3c-e). First, transcripts are still present in the presumed PDBG (Fig. 3c). Second, a deeper focal plane (Fig. 3d) reveals expression in a central patch of cells near the terminus of the anterodorsal cortex (see Winchell et al. 2010) and in large lateral domains that probably encompass brain and epidermal cells. Third, Nar-dac is active in three bilateral pairs of cell clusters in the ventral portion of the prostomium (Fig. 3e): between the antennae, in front of the ventral neuropil, and anterolaterally between the antennae and palps.

Infour-chaetigerjuveniles, Nar-dac-expressing cells of the presumed PDBG are positioned above the pharynx, in the dorsolateral corners of the prostomium (Fig. $3 \mathrm{~g}, \mathrm{~h}$ ). In the segmented portion of the body, Nar-dac transcripts accumulate in every ganglion of the nerve cord and in discrete
Fig. 2 Nar-Dll is expressed in developing appendages and the juvenile brain. a Hatchling stage, anteroventral view. Transcripts occur in rings around the developing palps (arrows) and anterior cirri (arrowheads) and as patches in the parapodial lobes. Dashed double arrowheads point to notopodia (out of focus); filled double arrowheads point to neuropodia. Brackets enclose expression in the brain, and dashed circles represent the stomodeum. b Posteroventral view of hatchling posterior end. The dashed black line denotes the ventral midline; the dashed red line marks the space between Nar-Dllexpressing parapodial lobes (kept unobstructed on the left-hand side). The neuropodia are to the left of the red line; the notopodia are to the right. c Hatchling posterior end; ventral view, anterior to the left. Dark lateral staining occurs in parapodial rudiments, and arrows point to the developing anal cirri. d-f Consecutive focal planes of a late threechaetiger juvenile head; dorsal view, anterior up, outlined with dashes. d Dorsal-most focal plane. Arrows point to Nar-Dll-expressing cell clusters in the posterior brain. e Middle focal plane. Expression occurs at the bases of the antennae (arrowheads) and in a pair of cell clusters in the lateral brain (arrows) - the "middle clusters". f Ventral-most focal plane. The dashed inner structure represents the brain's ventral neuropil. Prominent Nar-Dll expression occurs anterior to this neuropil (in the "anterior clusters"; arrowheads) and in the arcs of cells (arrows) between the neuropil and the anterior margin of the prostomium. g, h Four-chaetiger juvenile, ventral view. g Anterior end. Ring-like expression occurs at the bases of the palps (arrows) and anterior cirri (arrowheads). The asterisk marks the foregut. $\mathbf{h}$ Posterior end. The dashed line marks the boundary between the mesoderm and Nar-Dll-expressing ectoderm. i, j Third and fourth chaetigerous parapodia and first achaetigerous parapodium of a four-chaetiger juvenile. i Ventral view showing neuropodial expression. Arrows point to expression in presumed parapodial ganglia. $\mathbf{j}$ Dorsal view showing ring-like expression around the bases of developing dorsal cirri. $\mathbf{k}$ Five-chaetiger juvenile; lateral view, anterior to the left, dorsal up. Parapodia 1-4 are outlined. The second parapodium, denoted with an asterisk, is shown in transverse section in l (different specimen). Arrowheads mark nascent neuropodia with ring-like expression. I Transverse section of the second parapodium from a five-chaetiger juvenile. The neuropodial expression is marked by a bent line (dashes for faint expression, solid bar for more intense expression in the presumed parapodial ganglion). The ring-like expression occurs basally in the dorsal cirrus (arrow). m Transverse section of a fivechaetiger juvenile head (dorsal is up) showing the anterior pair of eyes (arrows) and Nar-Dll-expressing cells just below them (arrowheads). These cells represent the "middle clusters" (marked with arrows in e and $\mathbf{o}$ ). The asterisk denotes the foregut. $\mathbf{n}-\mathbf{p}$ Consecutive focal planes of an eight-chaetiger juvenile head (dorsal view, anterior up). n Dorsal-most focal plane showing expression in the posterior brain. Dashes outline the head (most of which is out of focus), and dashed circles represent the eyes. o Middle focal plane. Expression occurs laterally in the brain (the "middle clusters", arrows) and at the antennal bases (arrowheads). p Ventral-most focal plane. Dashes outline the ventral neuropil. Expression persists in the anterior cirri (at their bases, double arrowheads) and in the "anterior clusters" (arrows). q Eight-chaetiger juvenile head; ventral view, anterior up. The expression at the bases of the newly formed ventral pair of anterior cirri is marked with arrows, and double arrowheads point to expression in the palps. $\mathbf{r}$, s Eight-chaetiger juvenile posterior end; anterior to the left. Arrows point to basal staining in the anal cirri. $\mathbf{r}$ Ventral view. Arrowhead pairs indicate staining in a presumed parapodial ganglion. s Lateral view. Arrowheads mark nascent neuropodia with ring-like expression, and the dashed box specifies the notopodia shown in $\mathbf{t}$ (different specimen). $\mathbf{t}$ Posterior notopodia of an eight-chaetiger juvenile. Out-of-focus dorsal cirri are outlined 


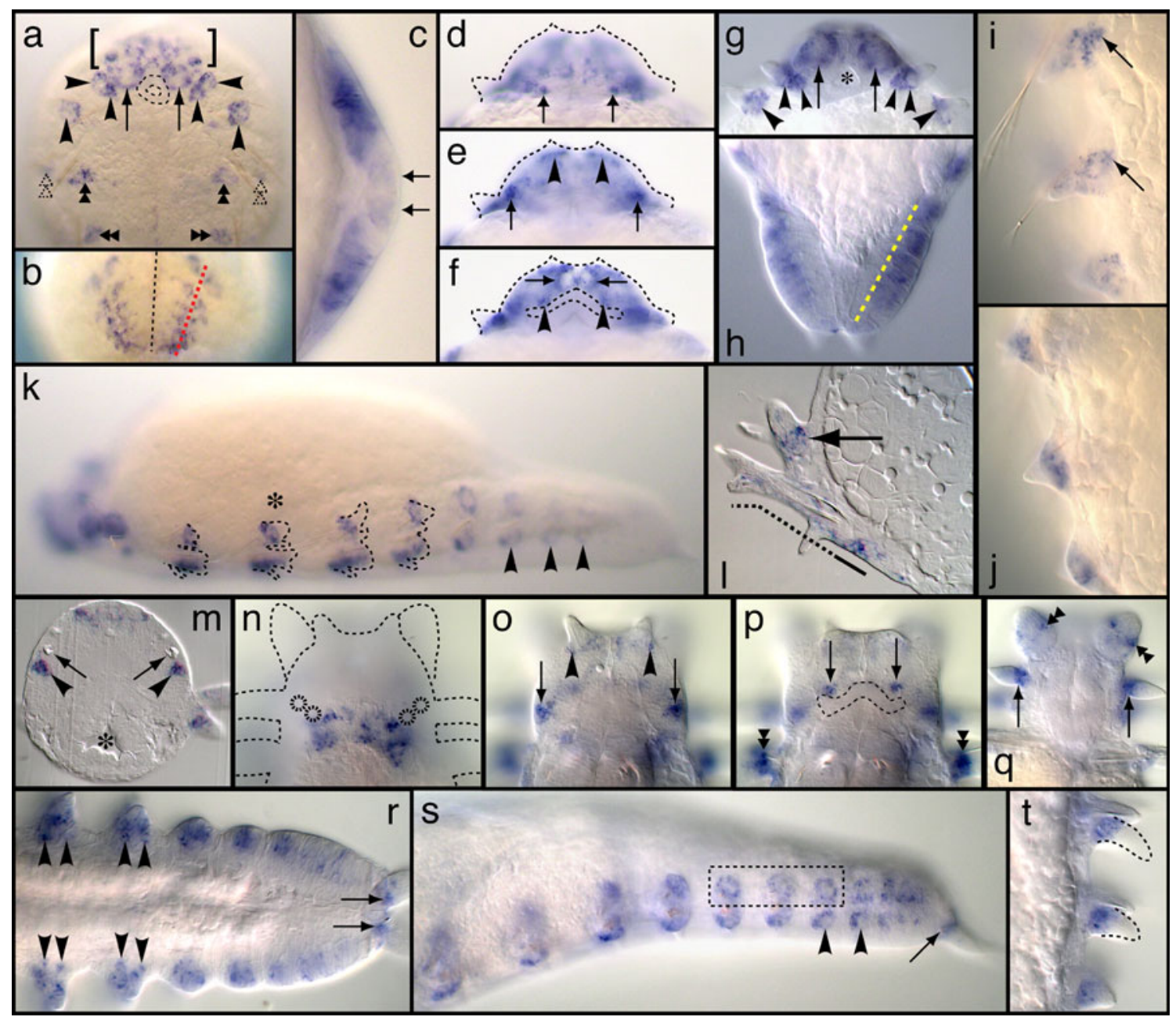

regions within the presumed PNS (Fig. 3h, i). These latter areas include a few cells (1) likely residing in the parapodial ganglia, (2) near the bases of the parapodial cirri (data shown only for the ventral cirri), and (3) just lateral to the VNC at the posterior parapodial bases. Because of their proximity to the posteromedial boundary of the parapodial ganglion, the latter cells are interpreted as interneurons connecting segmental nerves 2 and 4 (Smith 1957; Winchell et al. 2010), but further research is needed to verify this presumption. Similar patterns are present in the mid-body segments of eight-chaetiger juveniles (Fig. 31-n, v).

By the five-chaetiger stage, the posterior portion of the ventral brain contains scattered Nar-dac-expressing cells surrounding the "lateral common roots" (Fig. 3j). Expression in other parts of the brain: (1) ceases between the antennae, (2) persists just in front of the neuropil, in cells that appear to lie very near the roots of the second stomatogastric nerves (just lateral to the 1st pair's roots) (Winchell et al. 2010), and (3) diminishes in the anterolateral regions, occurring only at the edge of the prostomium. Figure $3 \mathrm{j}$ also reveals one or two Nar-dac-expressing cells at the bases of the anterior cirri. The eyes of five-chaetiger juveniles do not appear to express Nar-dac, although some epidermal cells just outside the eyes do (Fig. 3k), but this expression dissipates by the eight-chaetiger stage (Fig. 3t).

Transverse sections of an eight-chaetiger juvenile (Fig. 31-r) give a more detailed impression of how Nardac expression varies within the VNC. For example, in approximately the middle of the subesophageal ganglion (Fig. 3o), the highest abundance of transcripts is contained in just one or two cells on either side of the nerve tracts and neuropil of the cord. Between the second and third chaetigers (Fig. 3p), transcripts occur throughout a thick ventral domain but are more or less absent in the dorsal tips of the crescentic cell cortex. In an anterior region of the fifth chaetiger (Fig. 3q), transcripts are present throughout the cell cortex except within a broad medial domain. Near the interface of the sixth and seventh chaetigers (Fig. 3r), transcripts accumulate densely within the dorsal tips of the cell cortex, just lateral to the nerve tracts and neuropil, and lower expression levels occur in basally residing cells. 
Fig. 3 Nar-dac is expressed in the nervous system and newly differentiated mesoderm. a Hatchling; lateral view, anterior to the left, dorsal up. Transcripts are present in the pygidium (arrow), posterior mesoderm (arrowhead), nerve cord (dashed line), and prostomium (bracket). b Hatchling; anteroventral view, anterior to the top. Nar-dac expression associated with the cephalic nervous system is bracketed. Arrowheads indicate Nar-dac-expressing cells in the presumed posterodorsal-most brain ganglia (out of focus). Dashed circles represent the stomodeum. $\mathbf{c}-\mathbf{e}$ Contiguous focal planes of a mid three-chaetiger juvenile head; dorsal view, anterior to the top, outlined with dashes. c Dorsal-most focal plane. Brackets are aligned with Nar-dac-expressing cells of the presumed PDBG. d Middle focal plane. The arrow points to a small patch of Nar-dacexpressing cells in the anterior brain, and brackets indicate large lateral domains of expression. e Ventral-most focal plane. Two medial pairs of cell clusters express Nar-dac: one between the antennae (arrows) and the other just in front of the ventral neuropil (double arrowheads). Arrowheads mark anterolateral cell clusters. f Dorsal view; a mid three-chaetiger juvenile's posterior end (anterior to the left) showing expression in the youngest mesodermal tissue. g Four-chaetiger juvenile head; dorsal view, outlined with dashes. Arrowheads point to Nar-dac-expressing cells of the presumed PDBG. Inset shows a transverse section. Arrows point to the tips of the developing jaws. $\mathbf{h}$ Whole four-chaetiger juvenile; lateral view, anterior to the left, dorsal up. Expression occurs throughout the ventral nerve cord. An arrow marks mesodermal expression, and the arrowhead points to a PDBG. i Ventral view of chaetigers 2-4 of a four-chaetiger juvenile (anterior to the left). Expression is associated with the bases of ventral cirri (double arrowheads), the parapodial ganglia (arrowheads), and putative interneurons (arrows) of the peripheral nervous system. j, k Five-chaetiger juvenile head. j Ventral view; focal plane passes through the floor of the brain. Expression occurs in cells surrounding the "lateral common roots" (brackets), in a pair of cell clusters (double arrowheads) in front of the ventral neuropil (dashed curved lines), in one or two cells at the bases of anterior cirri (out of focus, arrows), and at the anterolateral edge of the prostomium (arrowheads). The dashed box outlines a portion of the image that was spliced in from a deeper (more dorsal) focal plane. k Dorsal view; head outlined with dashes. The specimen was flattened to bring the eyes into roughly the same focal plane. Dashed box represents the area magnified in the inset. The eyes are diagramed for clarity. I Whole eight-chaetiger juvenile in ventral view (anterior to the left) with nerve cord expression in focus. Dashed lines represent approximate planes of transverse section for subsequent panels. m Transverse section through the middle portion of the seventh chaetiger. The parapodial ganglion is outlined with dashes, and the nerve cord is encircled by a large dashed oval. $\mathbf{n}$ Transverse section through the posterior portion of the fifth chaetiger. An arrow points to a Nar-dac-positive cell near the base of the ventral cirrus, and an arrowhead points to presumed interneurons of the PNS. The nerve cord is circled. o Transverse section between the first and second chaetigers. Expression occurs within cells of the subesophageal ganglion (circled) and cell clusters (arrows) in the pharynx. Arrowheads mark the longitudinal nerve tracts of the ventral nerve cord. p-r Transverse sections through various levels of the ventral nerve cord (see panel l). Double arrowheads point to the longitudinal nerve tracts. s-u Contiguous focal planes of an eight-chaetiger juvenile head; dorsal view, anterior up. Dashes outline the out-offocus portions of the head, and dashed circles represent the eyes. s Dorsal-most focal plane. Arrows point to expression in the posterior pharynx (panel o shows this in cross-section). $\mathbf{t}$ Middle focal plane. Dashed boxes surround staining in the brain's anterodorsal cortex. Double arrowheads point to the anterior eyes, the internal dashed structure outlines visible neuropil in this focal plane, and arrows point to Nar-dac-positive cells just outside the neuropil. u Ventral-most focal plane. The expression here is equivalent to that reported for the five-chaetiger stage (j). v Ventral view (anterior to the left) of chaetigers 6-8 of an eight-chaetiger juvenile. Labeling is the same as for $\mathbf{i}$. $\mathbf{w}-\mathbf{y}$ Twelve-chaetiger juveniles. $\mathbf{w}$ Dorsal view of anterior end (anterior to the left). Arrowheads mark expression in the pharynx. x, y Ventral views of the six posterior-most segments; two focal planes. $\mathbf{x}$ Focal plane showing the nerve cord lying between the "wavy" tracts of ventral longitudinal muscle bands (double arrowheads). The putative Nar-dac-expressing PNS interneurons (arrowheads) at the posterior bases of the parapodia are lateral to these muscles. $\mathbf{y}$ Slightly deeper focal plane showing Nar-dac expression in presumed metanephridial anlagen (arrows). ac anterior cirri, an antennae, ja jaws, $p 1$ p2 p3, first through third parapodia, $p a$ parapodia, $p l$ palp, $p h$ pharynx, $v b$ vitreous bodies (the eye lenses), $v c$ ventral cirrus

In the cephalic region of eight-chaetiger juveniles, expression in the presumed PDBG is no longer detectable, but a new expression domain appears in a large pair of peripheral ganglia (Winchell et al. 2010) located dorsally within the pharynx behind the developing jaws (Fig. 3o, s). Prostomial Nar-dac expression behind the eyes of eight-chaetiger juveniles (Fig. 3s) is similar to that of Nar-Dll (Fig. 2n), both of which likely occur in several ganglia of the brain's posterodorsal cortex (Winchell et al. 2010). In the brain's anterodorsal cortex, near each of the four corners of visible neuropil, one or two cells show faint Nar-dac expression, as do bilateral groups of cells oriented more anteriorly (Fig. 3t). In the brain's anteroventral cortex, Nar-dac expression patterns are similar to those of five-chaetiger juveniles (compare Fig. $3 \mathrm{j}$ and $\mathrm{u}$ ) except that expression has ceased at the anterolateral edges of the prostomium.

By the 12-chaetiger stage, Nar-dac expression in the head drops to sparse levels, but expression in the pharyngeal ganglia (behind the jaws) is still readily detectable (Fig. 3w). Transcripts also appear abundant in posterior VNC ganglia (Fig. $3 \mathrm{x}, \mathrm{y}$ ) whereas expression is waning in the six or seven anterior-most segments (data not shown). The focal plane of
Fig. 3x demonstrates continued expression in the putative peripheral interneuronal connections between the second and fourth segmental nerves. A slightly deeper focal plane (Fig. 3y), at a level just deep to the ventral longitudinal muscle bands, shows expression in cells that appear to reside between the sheets of parietal coelothelium (outer coelomic epithelium) that comprise the intersegmental septa. These cells may represent the developing metanephridial funnels (Bartolomaeus 1999; Winchell et al. 2010).

\section{Expression of Nar-omb}

Like Nar-dac, the Neanthes omb ortholog does not appear to be expressed in a manner consistent with a role in appendage morphogenesis. Instead, its major domains of activity are in the developing brain and foregut, in presumed neural cells of the anal cirri and a single pair of anterior cirri, in segmentally iterated cells of the VNC and presumed PNS, and in dorsal cells of nascent segments that are presumed to be muscular.

At the hatching stage, Nar-omb expression in the brain (Fig. 4a) occurs in a large medial patch, in a bilateral pair of 


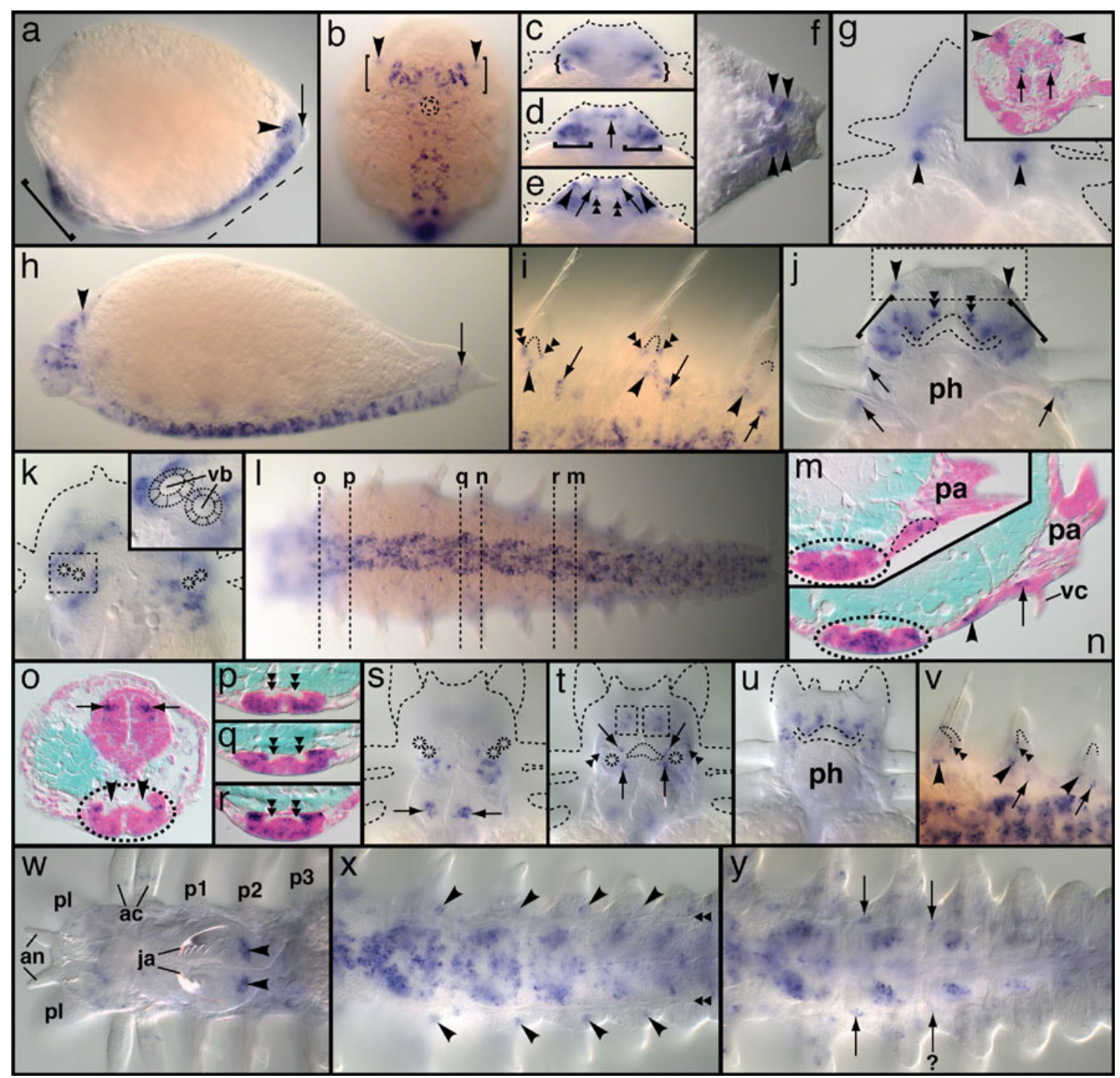

thin stripes (one on either side of the patch), and in small extensions (just two to three cells) projecting obliquely from the medial ends of the stripes toward the stomodeum. Expression also occurs in the stomodeum (Fig. 4a) and in nascent segments. In the latter, Nar-omb transcripts are present in bilateral pairs of iterated cell clusters lateral to the VNC (Fig. 4a) and in a bilateral pair of dorsal cell clusters (Fig. 4b). The developing anal cirri exhibit light expression (Fig. 4c).

In mid three-chaetiger juveniles, the medial patch of brain expression forms a V-like domain occupying a space just dorsal to the neuropil (Fig. 4d). At a level encompassing the middle portion of neuropil, Nar-omb transcripts are present in lateral regions of the prostomium (Fig. 4e) that appear to overlap with the Nar-Dll-expressing "middle clusters" (arrows in Fig. 2e). The stripes of Nar-omb expression referred to in the hatchling brain retain their roughly horizontal orientation but come to lie just behind the V-shaped domain, near the posterior margin of the brain (Fig. 4d). Stomodeal expression is limited to a dorsal domain (compare Fig. 4d and e) that encompasses the lateral sides and posterior boundary of the developing foregut (Fig. 4d). Dorsal expression at the posterior end is present in bilateral pairs of cell clusters in at least two (possibly three) preformed segments (Fig. 4f). These cells appear to reside just below the ectoderm, suggesting that they are mesodermal.

Several patterns of Nar-omb expression become more apparent by the four-chaetiger stage. First, as the anterior cirri develop in early juveniles, the posterior pair accumulates an abundance of Nar-omb transcripts (particularly at their bases) whereas the anterior pair lacks evidence of expression (Fig. 4g). Second, in each of the several young segments, most of the VNC staining occurs in paired cell clusters in the middle of the segment and in a row of cells that spans the width of the VNC near the posterior segment 
Fig. 4 Nar-omb is expressed in the juvenile central nervous system, foregut, dorsal mesoderm of nascent segments, and presumed PNS interneurons. a Ventral focal plane of hatchling; anterior to the top. Expression appears in the brain (bracketed), stomodeum (arrowheads), and cell clusters lateral to the VNC (out of focus, arrows). b, c Posterior end of hatchlings; anterior to the left. b Dorsal view. Expression appears in a pair of bilateral cell clusters (double arrowheads). c Ventral view. Arrows mark the expression in the anal cirri. d, e Contiguous focal planes of a mid three-chaetiger juvenile head outlined with dashes; dorsal view, anterior to the top. $\mathbf{d}$ Dorsal-most focal plane. Expression appears in the brain (medial, open double arrowheads; posterior, arrows) and stomodeum (lateral, arrowheads; posterior, closed double arrowheads). e Deeper (more ventral) focal plane. Arrows mark Nar-omb-expressing cell clusters in the lateral brain. The dashed internal structure represents the ventral neuropil. f Posterior end of a mid three-chaetiger juvenile; dorsal view, anterior to the top. Arrows point to expression in presumed mesodermal cell clusters in preformed segments. $\mathbf{g}-\mathbf{i}$ Four-chaetiger juveniles; anterior to the top. $\mathbf{g}$ Ventral view of head. Two pairs of anterior cirri are indicated: anterodorsal (arrowheads) and Nar-omb-expressing posterodorsal (arrows). h Ventral view focusing on the VNC. Two expression patterns are repeated in several young nerve cord ganglia (labeled only for one segment): a row of posterior cells (bracketed) and a pair of bilateral cell clusters anterior to these (arrows). Expression also appears in segmentally repeated cells of the presumed PNS (arrowheads). i Dorsal view. Brain expression and stomodeal expression are labeled as in $\mathbf{d}$, and white-filled arrowheads point to the Nar-omb-expressing dorsal cell clusters in nascent segments. j, k Contiguous focal planes of a five-chaetiger juvenile head; ventral view, anterior to the top. Asterisks label the foregut. $\mathbf{j}$ Ventral-most focal plane. Head is outlined with dashes. Black arrowheads point to expression near the bases of anteroventral anterior cirri (outlined with solid contours), and white arrowheads mark the expression in ephemeral chaetal protuberances associated with the posterodorsal anterior cirri. k Deeper (more dorsal) focal plane. Arrows mark the expression in cells of the palp bases; arrowheads mark the expression near the bases of anterodorsal anterior cirri; double arrowheads point to the posterodorsal anterior cirri, which express Nar-omb throughout their proximal ends. I, m Contiguous focal planes of a five-chaetiger juvenile posterior end; ventral view, anterior to the top. I Ventral-most focal plane emphasizing the segmentally iterated expression patterns in young nerve cord ganglia (labeled as in $\mathbf{h}$ ). $\mathbf{m}$ Deeper (more dorsal) focal plane slightly magnified relative to I. Arrowheads point to Nar-omb-expressing cell clusters of the presumed segmental PNS; these cells occur in preformed segments and reside near the posterior parapodial bases in older segments. Expression also occurs in basal cells of the anal cirri (arrows). n, o Contiguous focal planes of an eight-chaetiger juvenile head; dorsal view, anterior to the top. n Dorsal-most focal plane. Dashed lines represent the planes of transverse cross-sections shown in subsequent panels. o Deeper (more ventral) focal plane. Arrows point to the expression ventral to the anterior eyes. p Expression appears in the medial brain (double arrowheads) and below the anterior eyes (arrows; eyes labeled with arrowheads). q Expression in the posterior brain. $\mathbf{r}$ Expression in the posterodorsal anterior cirri. $\mathbf{s}$ Expression in the dorsal pharynx. $\mathbf{t}$ Expression in the anterior esophagus. u Posterior end of an eight-chaetiger juvenile (dorsal view, anterior to the top) showing expression in bilateral clusters of mesodermal cells (arrows) in preformed segments. The dashed line corresponds to the plane of transverse section in panel $\mathbf{v}$. $\mathbf{v}$ Expression appears in paired clusters of dorso-lateral mesodermal cells (arrows), just deep to the thin ectodermal layer. w-aa Thirteen-chaetiger juveniles. w Anterior end (dorsal view, anterior to the top) showing continued expression in the posterodorsal anterior cirri (arrows), the pharynx (arrowheads), and the anterior esophagus (bracketed). x Close-up of jaws and pharyngeal expression. $\mathbf{y}, \mathbf{z}$ Contiguous focal planes of head; dorsal views, anterior to the top. $\mathbf{y}$ Dorsal-most focal plane. Expression in the medial and posterior brain forms U-shaped patterns in each half of the prostomium. $\mathbf{z}$ Deeper (more ventral) focal plane showing faint expression in sub-ocular cells (arrows). aa Ventral view (anterior to the left) of the four posterior-most, parapodia-bearing segments plus two preformed segments anterior to the pygidium. The nerve cord lies between the "wavy" ventral longitudinal muscle bands (tracts indicated with double arrowheads). The dashed box encloses nerve cord expression on a segment boundary; otherwise, labeling follows that of $\mathbf{h}$

boundary (Fig. 4h). Third, Nar-omb activity in cells lateral to the VNC (described above for the hatchlings; arrows in Fig. 4a) persists in anterior segments (Fig. 4h). These cells appear to overlap with the presumed Nar-dac-positive PNS interneurons at the posterior parapodial bases (see below). A dorsal view of a four-chaetiger juvenile (Fig. 4i) echoes what was reported for earlier stages.

As shown in a five-chaetiger juvenile, several cells residing at the ventral bases of the developing cephalic appendages (excluding the antennae) exhibit Nar-omb activity (Fig. 4j, k). This expression occurs in the two anterior pairs (dorsal and ventral) of anterior cirri and in the ephemeral chaetal protuberances associated with the posterodorsal pair of anterior cirri. As described above, expression also occurs more distally throughout this pair of cirri. In the palps, ventral expression is most intense at their posterior borders and in anteromedially positioned cells; both of these domains may be associated with developing nerves of the palp walls (Orrhage 1993; Winchell et al. 2010). Ventral views of the posterior end of five-chaetiger juveniles show patterns in the nerve cord (Fig. 4l) and presumed PNS (Fig. $4 \mathrm{~m}$ ) that are equivalent to those of earlier stages. This includes faint expression occurring basally in the anal cirri (Fig. $4 \mathrm{~m}$ ) (this signal is present in all later stages examined; data not shown).

Cross-sections of an eight-chaetiger juvenile were prepared to better analyze Nar-omb expression in the cephalopharyngeal region (Fig. 4n-t). The expression domain in the medial brain (previously V-shaped but more or less solid at the eight-chaetiger stage; Fig. 4n) occurs dorsally, with its anterior extent falling between the pair of anterior eyes (Fig. 4p). The lateral cell clusters of the brain (described previously for the three-chaetiger stage; Fig. 4e) continue their expression (Fig. 4o) and, like the Nar-Dll-expressing "middle clusters", reside below the anterior eyes (compare Figs. $2 \mathrm{~m}$ and $4 \mathrm{p}$ ); hence, both genes may be expressed in developing Holmgren's cerebral commissural ganglia. A section through the posterior head reveals Nar-omb expression in superficial as well as deep (just above the pharynx) cells of the brain (Fig. 4q). The Nar-omb-expressing cells in the posterodorsal pair of anterior cirri appear to occupy a largely proximal core region (Fig. 4r). The expression of the foregut develops a new complexity, occurring in separate anterior and posterior portions (Fig. $4 \mathrm{n}$ ). The anterior signal 


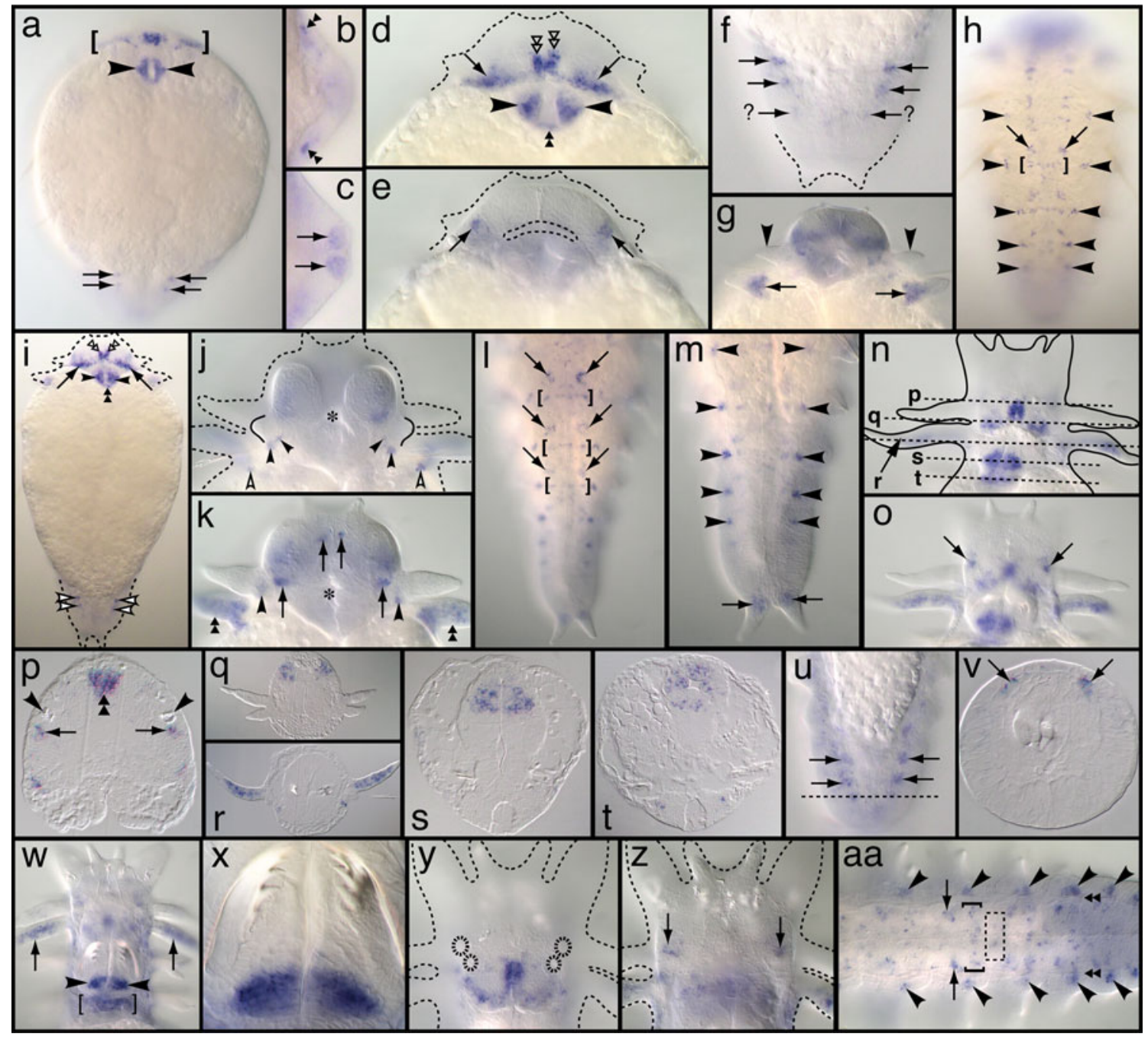

encompasses large bilateral cell clusters in the dorsal pharynx (Fig. 4s), and the posterior signal resides in cells of the sphincter-like opening to the esophagus (Fig. 4t). A cross-section through a preformed segment shows that the iterated dorsal cell clusters (identified above; Fig. 4b, f, i) are indeed mesodermal, assuming a position just below the ectoderm (Fig. $4 \mathrm{u}, \mathrm{v})$. These cells appear to co-localize with labeled actin filaments of either the dorsal longitudinal muscles or the proximal portions of dorsal parapodial muscles (Winchell et al. 2010) and hence may be muscle precursor cells.

Analysis of Nar-omb expression concluded with juveniles bearing 13 chaetigers. No novel patterns were encountered, but some previously described patterns resolve to finer detail. First, expression at the anterior end persists in the posterodorsal pair of anterior cirri, in the opening to the esophagus, and in the pharynx (Fig. 4w). In the latter, transcripts accumulate just posterior and medial to the jaws (Fig. 4x) - in the same presumed pharyngeal ganglia that exhibit Nar-dac activity (but Nar-omb is expressed more broadly; cf. Fig. 3w). Expression in both halves of the posterior and medial brain also persists, and these domains appear to have melded, forming large bilateral U-shaped patterns that contour the posterior margin of the prostomium and meet between the posterior eyes (Fig. 4y). Faint signal remains below each anterior eye in the presumed Holmgren's cerebral commissural ganglia (Fig. 4z). At the posterior end, expression patterns in young nerve cord ganglia echo those of earlier stages, except that staining becomes more apparent in a few cells occurring between some segments (Fig. 4aa). As in earlier stages, segmentally iterated clusters of Nar-omb-expressing cells occur near the posterior parapodial bases, just lateral to the "wavy" ventral longitudinal muscle bands (Fig. 4aa). These cells appear to co-localize with Nar-dac-expressing cells (compare Figs. 3x and 4aa) and the interneuronal connections between segmental nerves 2 and 4 (Winchell et al. 2010). Therefore, it is possible that these PNS interneurons 
express both genes during their development. The VNC and PNS patterns described here diminish in more anterior segments, presumably due to down-regulation of expression.

\section{Discussion}

Predictions and the relationship of parapodia to arthropodia

If appendage morphogenesis in Neanthes were to be governed by the same mechanisms that involve $\mathrm{Dll}$, dac, and $o m b$ homologs in arthropod or vertebrate appendages, then we would expect to observe the following patterns. First, Nar-Dll expression should occur conspicuously in the distal tips of outgrowing appendages. Second, Nar-dac expression should be consistent with a role in proximodistal pattern formation. Third, if annelid and arthropod mechanisms were to be homologous, then Nar-omb expression should occur in dorsal portions of developing appendages; but, if homology were shared between annelids and vertebrates, then Nar-omb expression should be consistent with a role in organizing the anteroposterior axial polarity of developing appendages. None of these predictions are upheld by the data presented here. The absence of Nar-Dll activity in distal portions of outgrowing appendages, plus the lack of Nar-dac and Nar-omb appendage expression in morphogenesis-like patterns, indicates that, relative to arthropods and vertebrates, annelids employ distinctive mechanisms of appendage development.

The preceding inference is based on only three genes and one annelid species and does not necessarily apply to all stages of appendage development (see below). However, it relates to a broader debate regarding the evolutionary relationship between polychaete parapodia and panarthropod limbs (lobopodia and arthropodia) (e.g., Westheide 1997; Giribet 2003) and, in our view, renders hypotheses of classical homology of these mature appendages less likely. Because parapodia and lobopodia/arthropodia share no intricate structural similarities and are only related tenuously on the simple condition of being ventrolateral segmental buds (Schmidt-Rhaesa et al. 1998), demonstration of classical homology would require highly compelling, "deep" similarities (i.e., in developmental-genetic mechanisms) (Shubin et al. 2009). With this perspective in mind, the work of Prpic (2008) warrants discussion. He found that the $\mathrm{Dll}$-expressing appendage primordia of the brine shrimp Artemia franciscana overlap with domains of wingless expression, which define the posterior parasegment boundaries, and lie behind domains of engrailed expression, which define the anterior parasegment boundaries. Because these patterns resemble the expression of orthologous genes in developing segments and parapodial primordia of Platynereis (Prud'homme et al. 2003; Saudemont et al. 2008), Prpic (2008) concluded that polychaete parapodia are parasegmental structures homologous to arthropod limbs. The likelihood of homoplasy in segmentation processes (Chipman 2010; Seaver and Kaneshige 2006; Shankland 2003) challenges this postulation, as does a more deconstructionist view of homology (Scholtz 2005, 2010). More specifically, Prpic's (2008) homology conceptualization conflates early ontogenetic characters and adult structures. Given the evidence for evolutionary independence of developmental stages (Scholtz 2005 and references therein), early ontogenetic similarities between taxa are most appropriate for supporting the homology of an early developmental stage or, combined with evidence of other homologous stages, an entire developmental sequence/process (Scholtz 2005). Accordingly, the similarities shown by Prpic (2008) suggest homology between annelid and arthropod appendage primordia, although the extent of this homology beyond gene expression/homocracy (Nielsen and Martinez 2003), i.e., whether it is mechanistic, cellular, or structural, is unclear and requires additional research. Also meriting future study is the possibility of two primordia per annelid parapodium, implied by the separate neuropodial and notopodial expression of $\mathrm{Nar}-\mathrm{Dll}$ in nascent segments.

Taken together, structural disparity and the absence of expected patterns of $\mathrm{Dll}$, dac, and omb expression in Neanthes strongly suggests that parapodia and arthropodia share no history as paired trunk appendages and that their outgrowth occurs via divergent mechanisms. As a caveat to this conclusion, divergent genetic networks often regulate the development of homologous structures (Scholtz 2005; Wagner 2007; Wray and Abouheif 1998); consequently, absence of comparable gene expression patterns cannot disprove classical homology. Nevertheless, molecular-phylogenetic findings further complicate any argument for homology of parapodia and arthropodia. Although the internal relationships of Lophotrochozoa and Ecdysozoa are not settled or always robustly supported, recent studies representing a variety of sequence data and analytical techniques consistently show derived positions for annelids and/or panarthropods; basal branches within Lophotrochozoa and/or Ecdysozoa are instead represented by taxa without segments and annelidor arthropod-like appendages (e.g., Dunn et al. 2008; Hausdorf et al. 2007; Hejnol et al. 2009; Mallatt and Giribet 2006; Mallatt et al. 2010; Paps et al. 2009a, b). Moreover, some phylogenies (e.g., Paps et al. 2009a, b; Wallberg et al. 2007) support the placement of two separate clades of simple acoelomate worms (Acoela and Nemertodermatida) at the base of the Bilateria. As a corollary, modern phylogenies find little evidence to 
support the evo-devo interpretations (e.g., Balavoine and Adoutte 2003; Dray et al. 2010; Prpic 2008) of segmented or paired-appendage-bearing bilaterian/protostome ancestors. The widely conserved developmental-genetic patterns across the Bilateria do suggest common origins of anteroposterior axial determination and elongation via an evolutionarily flexible terminal addition process (Chipman 2010; Jacobs et al. 2005).

Appendicular Nar-Dll expression and the evolution of Distal-less function

With the possible exception of antennae, whose premorphogenetic positions were difficult to pinpoint, Nar-Dll is expressed in all nascent appendages. Expression near the antennal bases is present during their initial outgrowth (late three-chaetiger stage), but this may occur in the underlying brain or antennal ganglia (Winchell et al. 2010). Despite this uncertainty, the general correspondence of Nar-Dll transcripts with pre-formed appendages accords with $D l l$ activity in a distantly related polychaete (Chaetopterus) and a host of other phyla (Onychophora, Arthropoda, Echinodermata, Urochordata, and Vertebrata) (Panganiban et al. 1997). As classical homology is unlikely across this range of appendages, the common expression of $\mathrm{Dll}$ in appendage primordia, typically followed by a dynamic shift to distal expression, may reflect a symplesiomorphic role for this gene in regulating a basic developmental process, possibly occurring in multiple contexts (Panganiban 2000), that has been recruited repeatedly in the evolution of diverse bilaterian appendages (Giribet 2003; Nielsen and Martinez 2003; Schmidt-Rhaesa et al. 1998). Various proposals for such a process include cell proliferation (Gorfinkiel et al. 1997; Nielsen and Martinez 2003), adhesion (Aspöck and Bürglin 2001; Campbell and Tomlinson 1998), shape changes, and migration (Panganiban 2000). A key finding in Neanthes is that $D l l$ transcripts do not ultimately become confined to the distal portions of outgrowing appendages. This situation is at odds with the conventional hypothesis of a protostome-deuterostome ancestor (PDA) possessing simple appendages that required $\mathrm{Dll}$ for their distal pattern formation (Tabin et al. 1999; Panganiban et al. 1997). Therefore, in outgrowing appendages, Nar-Dll appears to be active in an "atypical" context not directly related to distal patterning - although this does not refute a possible role in cell proliferation, adhesion, or migration, etc. The pertinent questions now become: what is this context, and is NarDll's involvement plesiomorphic or derived?

A primitive role for $\mathrm{Dll}$ in nervous system differentiation is thought to have predated its utility in bilaterian appendages (Panganiban et al. 1997). Dll in arthropods is expressed in numerous types of setose sensory organs (Angelini and Kaufman 2005; Cohen and Jürgens 1989;
Gorfinkiel et al. 1997; Mittmann and Scholtz 2001; Williams et al. 2002). These findings are consistent with the mutant phenotypes of Drosophila embryos null for Dll, which lack the setose sensory organs of the rudimentary antennae, mouthparts, and legs (Cohen and Jürgens 1989). In addition, marginal cells of adult Drosophila wings with Dll null alleles fail to form sensory bristles (Campbell and Tomlinson 1998; Gorfinkiel et al. 1997). Remarkably, the anterior sensilla of the nematode Caenorhabditis elegans are also Dll-positive (Aspöck and Bürglin 2001); hence, Dll's association with sensilla may be plesiomorphic for ecdysozoans. Chordates, too, show distinctive $\mathrm{Dll}$ activities in the PNS. For example, Dll paralogs in the ascidian Ciona intestinalis are expressed in neural placode-like structures (Irvine et al. 2007) and in the larval adhesive papillae (Caracciolo et al. 2000), which house prominent clusters of sensory neurons (Imai and Meinertzhagen 2007). Dll paralogs in the mouse are expressed, for example, in the brachial plexus nerve trunks (most likely in glia), in the sciatic plexus nerve roots, and in cranial nerve ganglia, where $D l x-2$ appears to control nerve arborization (Dollé et al. 1992; Qiu et al. 1995).

Citing Dll's activity/function in arthropod sensory organs, insufficient evidence for appendages in the PDA, and the fact that certain arthropod appendages form without Dll activity, Mittmann and Scholtz (2001) postulated that the evolution of bilaterian appendages began as a result of natural selection favoring higher-profile sensory organs (which are better able to detect environmental stimuli) and that $D l l$ was involved only in the differentiation of the sensory organ nervous system, not in the outgrowth process. The primitive sensory outgrowths were the antecedents of locomotory appendages, and only later, through independent recruitment in several bilaterian lineages, did $\mathrm{Dll}$ come to have a role in appendage formation (see also Jacobs et al. (2007) for a discussion regarding the potential common origins of sensory organs and appendages). With this perspective in mind, the hypothesis favored here is that Nar-Dll expression in outgrowing appendages reflects a primitive role (one passed on from the PDA or even the bilaterian ancestor) in the sensory development of the PNS.

Two interpretations regarding the ring-like expression in the sensory palps and cirri of Neanthes are plausible. The first, in line with Mittmann and Scholtz's (2001) hypothesis, accounts for the possibility that these cells are neurons of serially homologous sensory organs whose evolutionary origins may have been in two-dimensional structures. That the more distal palpal and cirral sensory cells lack Nar-Dll expression suggests functional divergence between them and the basal Nar-Dll-expressing cells. In keeping with this, ultrastructural evidence suggests a chemosensory role for these appendages in general (Boilly-Marer 1972; Dorsett and 
Hyde 1969), but electrophysiological data point to a mechanosensory function for basal cells of the dorsal cirri (Dorsett 1964). The second interpretation relates to the fact that Nar-Dll signal in the palps and cirri occurs approximately where afferent nerve processes of the numerous, more distal sensory organs fasciculate together to form a definite nerve (Winchell et al. 2010). Interestingly, Nar-Dll expression is absent in parapodial ventral cirri, and no single nerve forms at their bases; multiple nerve fibers instead pass to different locations in the parapodial ganglion (Winchell et al. 2010). This suggests that Nar-Dll activity promotes the differentiation of cells - possibly glia - that facilitate axonal guidance and/or bundling in the palps and bases of the anterior, dorsal, and anal cirri. In Drosophila and grasshopper embryos, peripheral glia have been shown to act as guideposts, providing cues that keep growing axons on the proper trajectory (Bastiani and Goodman 1986; Hidalgo 2003; Sepp et al. 2001). In later development, these same glia are necessary for the tight bundling of peripheral nerves (Sepp et al. 2001). Lastly, if the ventral neuropodial Nar-Dll signal correlates with sensory innervation, then it too can be attributed to a role in PNS sensory differentiation. Indeed a major parapodial nerve, pn2, divides at the base of the ventral neuropodium, courses along its anterior and posterior walls, and receives the central processes of various neuropodial sensory receptor types, e.g., of the ligule, chaetae, and anterior/posterior integument (Dorsett 1964; Hamaker 1898; Winchell et al. 2010).

The above interpretations of Nar-Dll expression are subject to confirmation (e.g., demonstration of colocalization of $\mathrm{Dll}$ transcripts with neural markers) and await careful analyses of appendage morphogenesis with special attention to mitotic activity and cell fates. Such analyses will elucidate whether Dll expression domains correlate with regions of intense cell proliferation potentially driving appendage outgrowth and whether its expression prior to outgrowth occurs in cells destined for the distal appendage (thereby implicating $\mathrm{Dll}$ in distal patterning of annelid appendages). Also meriting further investigation is the intriguing hypothesis of Panganiban and Rubenstein (2002), which is consistent with the potential homology of annelid and arthropod appendage primordia (see the previous section), at least at the level of cell type. They posited a conserved bilaterian role for wingless-induced Dll expression in the differentiation of migratory cells deriving from the outer margins of neuroectoderm, and they argued that such cells in model bilaterians ultimately form taxonspecific derivatives, e.g., Drosophila limb primordia and vertebrate neural crest. The expression of wingless and Distal-less in the lateral neuroectoderm of Platynereis trochophores (Denes et al. 2007; Prud'homme et al. 2003) hints that this scenario applies to nereidid parapodial primordia.
Cephalic expression of Nar-Dll, Nar-dac, and Nar-omb

Common to all three genes is activity in the posterodorsal part of the prostomium (behind the eyes). Although further investigation is required to resolve the identities of cells and structures in this head region, salient features include the chemosensory nuchal organs, their ganglia, and several other brain ganglia thought to be important hormonereleasing centers controlling growth and sexual maturation (e.g., Bell and Marsden 1980; Golding and Whittle 1977; Winchell et al. 2010).

The optic lobes of arthropod brains are major expression domains for $\mathrm{Dll}$, dac, and omb orthologs (Inoue et al. 2004; Janssen et al. 2008; Panganiban and Rubenstein 2002; Pflugfelder et al. 1992; Prpic and Tautz 2003; Prpic et al. 2005). Similar structures are known in only a few polychaete families (Alciopidae, Eunicidae, Phyllodocidae) (Bullock and Horridge 1965), suggesting that optic ganglia evolved convergently between annelids and arthropods and perhaps within annelids. Despite this, a pair of cephalic ganglia - the presumed Holmgren's cerebral commissural ganglia (gHo) - exhibits the expression of both Nar-Dll and Nar-omb. gHo among polychaetes are tacitly considered classical homologs, and their widespread occurrence suggests that they constitute a part of the annelid ground plan (Orrhage and Müller 2005 and references therein). Therefore, it is tempting to predict $D l l$ and omb activity in other polychaetes' developing gHo.

An important aspect of bilaterian dac homologs is their expression/function in photoreceptor development (Candiani et al. 2003; Davis et al. 1999; Hammond et al. 1998, 2002; Heanue et al. 2002; Inoue et al. 2004; Mardon et al. 1994; Yang et al. 2009). The large lateral domains of Nar-dac expression in the prostomium of mid three-chaetiger juveniles appear to overlap with the positions of developing eyes, but its expression was not confirmed in the nascent eyes proper. In five-chaetiger juveniles, Nar-dac transcripts are clearly absent from the eyes but present in epidermal cells peripheral to them. It is possible that Nar-dac activity in the prostomial epidermis surrounding the eyes serves to specify precursor cells that are later incorporated into the growing eyes, but even this expression all but disappears by the eightchaetiger stage. At this point, the eyes are still very small and will continue to grow and differentiate, most likely by adding many more sensory and supporting cells (Rhode 1992). The absence of dac expression in the growing eyes of Neanthes is remarkable because adult eye development in Platynereis proceeds without expression of eyeless/Pax6, another gene thought to have a conserved role in bilaterian photoreceptor development (Arendt et al. 2002). eyeless/Pax6 and dachshund are members of a regulatory network also involving eyes 
absent and sine oculis/Six homologs that was first discovered in Drosophila retinal determination and subsequently found to be more or less conserved in various contexts in other animals (e.g., Kozmik et al. 2007; Pappu and Mardon 2004). While this entire network evidently does not play a critical role in the growth and differentiation of nereidid adult eyes, sine oculis does show activity during adult eye development in Platynereis (Arendt et al. 2002).

Another important issue concerning dachshund homo$\operatorname{logs}$ is their activity in bilaterian brain centers responsible for higher-order processes (e.g., learning, memory, sensory integration). Examples of such centers include the mushroom bodies (MBs) of most panarthropod groups, the corpora pedunculata $(\mathrm{CP}$; also called $\mathrm{MBs}$ due to their similarity) of certain annelids, and the vertebrate pallium. Tomer et al. (2010) revealed strikingly similar molecular signatures - including dac expression - in developing Platynereis $\mathrm{CP}$, Drosophila MBs, and the mammalian pallium, concluding that the shared developmental mechanisms reflect deep homology and that the structures themselves are historically related to simpler sensory-associative brain centers that were present in the PDA. The Nar-dac expression in cells surrounding the "lateral common roots" (Fig. 3d, j, u) is consistent with the dac expression domains in Platynereis that overlap with developing CP (Tomer et al. 2010). In Neanthes, this staining becomes sparse by the 12-chaetiger stage, suggesting an attenuating role for $d a c$ in further CP development. This contrasts with Drosophila MBs, which exhibit strong and persistent $d a c$ expression in adults (Martini et al. 2000).

While it seems likely that the elaborate higher brain centers (pallium and MB-like structures including $\mathrm{CP}$ ) of modern bilaterians evolved from much simpler precursors in the PDA brain (Tomer et al. 2010), the hypothesized classical homology of protostome MB-like structures (e.g., Bullock and Horridge 1965; Heuer and Loesel 2008; Scholtz 2002) is severely challenged by their highly disjunctive phylogenetic distribution. In lophotrochozoans, such structures have so far been documented in only polyclad flatworms and certain annelid genera of the distantly related ordinal taxa Phyllodocida and Sabellida (see Heuer et al. 2010). No evidence exists for complex MB-like structures in basal ecdysozoans; the same is true for crustaceans (Strausfeld et al. 1998), including branchiopods (Kirsch and Richter 2007), the probable ancestors of hexapods (Mallatt and Giribet 2006; Telford et al. 2008). Therefore, complex MB-like structures most likely had multiple independent origins - even within Arthropodaduring the radiation of protostomes (Farris 2008). An alternative but far less parsimonious scenario is the widespread reduction or loss of these structures, perhaps due to fitness gains associated with regressive brain evolution during ecological specialization (Heuer et al. 2010 and references therein).

The final point on the cephalic region concerns Nar-omb expression in the anterior cirri. Among these sensory appendages, most omb activity is limited to the posterodorsal pair; the other pairs (anterodorsal and anteroventral) show comparatively little expression. We speculate that this pronounced difference amounts to functional divergence among the anterior cirri. Perhaps Nar-omb activity in the posterodorsal pair promotes the differentiation of unique sensory receptors that endow these cirri with special sensitivity to environmental chemicals not sensed by other cirri. An alternative scenario is that Nar-omb functions in the cephalization of the posterodosal cirri, which change from chaetigerous parapodia-like structures in early juveniles to long, chaeta-less head appendages by the 13chaetiger stage (Winchell et al. 2010).

Annelid appendage genes — are any known?

The expression patterns of an assortment of genes imply functionality in parapodial morphogenesis in appendagebearing model annelids, namely, Chaetopterus and Nereididae. The engrailed ortholog of Chaetopterus appears to be involved in the mesodermal morphogenesis of segmentspecific feeding structures, which are parapodial derivatives (Seaver et al. 2001), but this expression pattern is not conserved throughout Annelida because engrailed transcripts are absent in the outgrowing parapodia of Platynereis (Prud'homme et al. 2003). Various Platynereis genes do exhibit ectodermal striped, segment polarity-like expression that extends laterally from nascent segments into outgrowing parapodia: a wingless ortholog is expressed along a narrow posterior margin (Prud'homme et al. 2003), and the NK homeobox genes drop and ladybird are expressed in the middle and posterior ectoderm, respectively (Saudemont et al. 2008). Additionally, drop and other NK genes, slouch and $C 15$, are expressed in ventral trunk mesoderm in patterns that bespeak an identity-assigning role for different parapodial muscle precursors (Saudemont et al. 2008). More recently, several genes of the hedgehog signaling pathway, namely, hedgehog, patched, and Cubitus interruptus, have been shown to be active in the ectoderm of developing Platynereis parapodia (Dray et al. 2010). The hedgehog pathway is also active in Drosophila appendage primordia (imaginal discs), indicating partial similarity of developmental mechanisms, but the expression of the aforementioned genes differs markedly in terms of relative overlap and topography within the discs (Dray et al. 2010); hence, substantial regulatory differences seem to have evolved between these taxa. Lastly, appendage formation in Chaetopterus and Nereididae is accompanied by Hox expression that coincides with Hox regionalization of the anteroposterior 
body axis (Irvine and Martindale 2000; Kulakova et al. 2007). This is akin to Hox expression in arthropods (Hughes and Kaufman 2002) and likely reflects the ancestral role of bilaterian Hox genes (Carroll et al. 2005). In contrast, the complex patterns of Hox expression in developing tetrapod limbs (Carroll et al. 2005) are the result of gene duplication combined with co-option of genes that originally functioned in patterning the anteroposterior body axis (Shubin et al. 1997).

Acknowledgments We thank Elaine Seaver for technical advice, Volker Hartenstein for discussion and use of sectioning equipment, and two anonymous reviewers for their valuable suggestions. This work was supported by a GAANN fellowship to CJW and NASA Astrobiology funding to DKJ.

Open Access This article is distributed under the terms of the Creative Commons Attribution Noncommercial License which permits any noncommercial use, distribution, and reproduction in any medium, provided the original author(s) and source are credited.

\section{References}

Abascal R, Zardoya R, Posada D (2005) ProtTest: selection of best-fit models of protein evolution. Bioinformatics 21:2104-2105

Abouheif E (1997) Developmental genetics and homology: a hierarchical approach. Trends Ecol Evol 12:405-408

Abzhanov A, Kaufman TC (2000) Homologs of Drosophila appendage genes in the patterning of arthropod limbs. Dev Biol 227:673-689

Altschul SF, Madden TL, Schäffer AA, Zhang J, Zhang Z, Miller W, Lipman DJ (1997) Gapped BLAST and PSI-BLAST: a new generation of protein database search programs. Nucleic Acids Res 25:3389-3402

Angelini DR, Kaufman TC (2004) Functional analyses in the hemipteran Oncopeltus fasciatus reveal conserved and derived aspects of appendage patterning in insects. Dev Biol 271:306-321

Angelini DR, Kaufman TC (2005) Insect appendages and comparative ontogenetics. Dev Biol 286:57-77

Arendt D, Tessmar K, Medeiros de Campos-Baptista M-I, Dorresteijn A, Wittbrodt J (2002) Development of pigment-cup eyes in the polychaete Platynereis dumerilii and evolutionary conservation of larval eyes in Bilateria. Development 129:1143-1154

Arthur W, Jowett T, Panchen A (1999) Segments, limbs, homology, and co-option. Evol Dev 1:74-76

Aspöck G, Bürglin TR (2001) The Caenorhabditis elegans Distal-less ortholog ceh-43 is required for development of the anterior hypodermis. Dev Dyn 222:403-409

Balavoine G, Adoutte A (2003) The segmented Urbilateria: a testable scenario. Integr Comp Biol 43:137-147

Bartolomaeus T (1999) Structure, function and development of segmental organs in Annelida. Hydrobiologica 402:21-37

Bastiani MJ, Goodman CS (1986) Guidance of neuronal growth cones in the grasshopper embryo. III. Recognition of specific glial pathways. J Neurosci 6:3542-3551

Bell K, Marsden JR (1980) Age-related histological changes in neurosecretory cells in the supraoesophageal ganglion of Nereis virens (Annelida, Polychaeta). Can J Zool 58:1735-1740

Boilly-Marer Y (1972) Etude ultrastructurale des cirres parapodiaux de Nereidiens atoques (Annélides Polychètes). Z Zellforsch 131:309-327
Brook WJ, Cohen SM (1996) Antagonistic interactions between Wingless and Decapentaplegic responsible for dorsal-ventral pattern in the Drosophila leg. Science 273:1373-1377

Bullock TH, Horridge GA (1965) Structure and function in the nervous system of invertebrates, vol 1. Freeman, San Francisco

Campbell G, Tomlinson A (1998) The roles of the homeobox genes aristaless and Distal-less in patterning the legs and wings of Drosophila. Development 125:4483-4493

Candiani S, Kreslova J, Benes V, Oliveri D, Castagnola P, Pestarino M, Kozmik Z (2003) Cloning and developmental expression of amphioxus Dachshund. Gene Expr Patterns 3:65-69

Caracciolo A, Di Gregorio A, Aniello F, Di Lauro R, Branno M (2000) Identification and developmental expression of three Distal-less homeobox containing genes in the ascidian Ciona intestinalis. Mech Dev 99:173-176

Carroll SB, Grenier JK, Weatherbee SD (2005) From DNA to diversity: molecular genetics and the evolution of animal design, 2nd edn. Blackwell, Malden

Chipman AD (2010) Parallel evolution of segmentation by co-option of ancestral gene regulatory networks. BioEssays 32:60-70

Cohen SM, Jürgens G (1989) Proximal-distal pattern formation in Drosophila: cell autonomous requirement for Distal-less gene activity in limb development. EMBO J 8:2045-2055

Cohen SM, Brönner G, Küttner F, Jügerns G, Jäckle H (1989) Distal-less encodes a homeodomain protein required for limb development in Drosophila. Nature 338:432-434

Davis RJ, Shen W, Heanue TA, Mardon G (1999) Mouse Dach, a homologue of Drosophila dachshund, is expressed in the developing retina, brain, and limbs. Dev Genes Evol 209:526536

Denes AS, Jékely G, Steinmetz PRH, Raible F, Snyman H, Prud'homme B, Ferrier DEK, Balavoine G, Arendt D (2007) Molecular architecture of annelid nerve cord supports common origin of nervous system centralization in Bilateria. Cell 129:277-288

Desper R, Gascuel O (2002) Fast and accurate phylogeny reconstruction algorithms based on the minimum-evolution principle. J Comput Biol 9:687-705

Dickinson WJ (1995) Molecules and morphology: where's the homology? Trends Genet 11:119-121

Dollé P, Price M, Duboule D (1992) Expression of the murine Dlx-1 homeobox gene during facial, ocular and limb development. Differentiation 49:93-99

Dorsett DA (1964) The sensory and motor innervation of Nereis. P Roy Soc Lond B Bio 159:652-657

Dorsett DA, Hyde R (1969) The fine structure of the compound sense organs on the cirri of Nereis diversicolor. Z Zellforsch 97:512 527

Dray N, Tessmar-Raible K, Le Gouar M, Vibert L, Christodoulou F, Schipany K, Guillou A, Zantke J, Snyman H, Béhague J, Vervoort M, Arendt D, Balavoine G (2010) Hedgehog signaling regulates segment formation in the annelid Platynereis. Science 329:339-342

Dunn CW, Hejnol A, Matus DQ et al (2008) Broad phylogenomic sampling improves resolution of the animal tree of life. Nature 452:745-750

Farris SM (2008) Evolutionary convergence of higher brain centers spanning the protostome-deuterostome boundary. Brain Behav Evol 72:106-122

Felsenstein J (2005) PHYLIP (Phylogeny Inference Package) version 3.6 (distributed by the author). Department of Genome Sciences, University of Washington, Seattle

Gibson-Brown JJ, Agulnik SI, Chapman DL, Alexiou M, Garvey N, Silver LM, Papaioannou VE (1996) Evidence of a role for T-box genes in the evolution of limb morphogenesis and the specification of forelimb/hindlimb identity. Mech Dev 56:93-101 
Giribet G (2003) Molecules, development and fossils in the study of metazoan evolution; Articulata versus Ecdysozoa revisited. Zoology 106:303-326

Golding DW, Whittle AC (1977) Neurosecretion and related phenomena in annelids. Int Rev Cytol Suppl 5:189-302

Gorfinkiel N, Morata G, Guerrero I (1997) The homeobox gene Distal-less induces ventral appendage development in Drosophila. Genes Dev 11:2259-2271

Guindon S, Gascuel O (2003) A simple, fast, and accurate algorithm to estimate large phylogenies by maximum likelihood. Syst Biol 52:696-704

Hamaker JI (1898) The nervous system of Nereis virens Sars. A study in comparative neurology. Bull Mus Comp Zool Harv 32:89-124

Hammond KL, Hanson IM, Brown AG, Lettice LA, Hill RE (1998) Mammalian and Drosophila dachshund genes are related to the Ski proto-oncogene and are expressed in eye and limb. Mech Dev 74:121-131

Hammond KL, Hill RE, Whitfield TT, Currie PD (2002) Isolation of three zebrafish dachshund homologues and their expression in sensory organs, the central nervous system and pectoral fin buds. Mech Dev 112:183-189

Hausdorf B, Helmkampf M, Meyer A, Witek A, Herlyn H, Bruchhaus I, Hankeln T, Struck TH, Lieb B (2007) Spiralian phylogenomics supports the resurrection of Bryozoa comprising Ectoprocta and Entoprocta. Mol Biol Evol 24:2723-2729

Heanue TA, Davis RJ, Rowitch DH, Kispert A, McMahon AP, Mardon G, Tabin CJ (2002) Dach1, a vertebrate homologue of Drosophila dachshund, is expressed in the developing eye and ear of both chick and mouse and is regulated independently of Pax and Eya genes. Mech Dev 111:75-87

Hejnol A, Obst M, Stamatakis A, Ott M, Rouse GW, Edgecombe GD, Martinez P, Baguñà J, Bailly X, Jondelius U, Wiens M, Müller WEG, Seaver E, Wheeler WC, Martindale MQ, Giribet G, Dunn CW (2009) Assessing the root of bilaterian animals with scalable phylogenomic methods. Proc R Soc B 27:4261-4270

Heuer CM, Loesel R (2008) Three-dimensional reconstruction of mushroom body neuropils in the polychaete species Nereis diversicolor and Harmothoe areolata (Phyllodocida, Annelida). Zoomophology 128:219-226

Heuer CM, Müller CHG, Todt C, Loesel R (2010) Comparative neuroanatomy suggests repeated reduction of neuroarchitectural complexity in Annelida. Front Zool 7:13

Hidalgo A (2003) Neuron-glia interaction during axon guidance in Drosophila. Biochem Soc Trans 31:50-55

Horner A, Shum L, Ayres JA, Nonaka K, Nuckolls GH (2002) Fibroblast growth factor signaling regulates Dach1 expression during skeletal development. Dev Dyn 225:35-45

Hughes CL, Kaufman TC (2002) Hox genes and the evolution of the arthropod body plan. Evol Dev 4:459-499

Imai JH, Meinertzhagen IA (2007) Neurons of the ascidian larval nervous system in Ciona intestinalis: II. Peripheral nervous system. J Comp Neurol 501:335-352

Inoue Y, Mito T, Miyawaki K, Matsushima K, Shinmyo Y, Heanue TA, Mardon G, Ohuchi H, Noji S (2002) Correlation of expression patters of homothorax, dachshund, and Distal-less with the proximodistal segmentation of the cricket leg bud. Mech Dev 113:141-148

Inoue Y, Miyawaki K, Terasawa T, Matsushima K, Shinmyo Y, Niwa N, Mito T, Ohuchi H, Noji S (2004) Expression patterns of dachshund during head development of Gryllus bimaculatus (cricket). Gene Expr Patterns 4:725-731

Irvine SQ, Martindale MQ (2000) Expression patterns of anterior Hox genes in the polychaete Chaetopterus: correlation with morphological boundaries. Dev Biol 217:333-351

Irvine SQ, Cangiano MC, Millette BJ, Gutter ES (2007) Nonoverlapping expression patterns of the clustered $D l l-A / B$ genes in the ascidian Ciona intestinalis. J Exp Zool (Mol Dev Evol) 308B:428-441

Jacobs DK, Hughes NC, Fitz-Gibbon ST, Winchell CJ (2005) Terminal addition, the Cambrian radiation and the Phanerozoic evolution of bilaterian form. Evol Dev 7:498-514

Jacobs DK, Nakanishi N, Yuan D, Camara A, Nichols SA, Hartenstein V (2007) Evolution of sensory structures in basal metazoa. Integr Comp Biol 47:712-723

Janssen R, Feitosa NM, Damen WGM, Prpic N-M (2008) The T-box genes H15 and optomotor-blind in the spiders Cupiennius salei, Tegenaria atrica, and Achaeranea tepidariorum and the dorsoventral axis of arthropod appendages. Evol Dev 10:143-154

Janssen R, Joakim Eriksson B, Budd GE, Akam M, Prpic N-M (2010) Gene expression patterns in an onychophoran reveal that regionalization predates limb segmentation in pan-arthropods. Evol Dev 12:363-372

Kida Y, Maeda Y, Shiraishi T, Suzuki T, Ogura T (2004) Chick Dach1 interacts with the Smad complex and Sin3a to control AER formation and limb development along the proximodistal axis. Development 131:4179-4187

Kirsch R, Richter S (2007) The nervous system of Leptodora kindtii (Branchiopoda, Cladocera) surveyed with confocal scanning microscopy (CLSM), including general remarks on the branchiopod neuromorphological ground pattern. Arthropod Struct Dev $36: 143-156$

Kojima T (2004) The mechanism of Drosophila leg development along the proximodistal axis. Dev Growth Differ 46:115-129

Kozmik Z, Pfeffer P, Kralova J, Paces J, Paces V, Kalousova A, Cvekl A (1999) Molecular cloning and expression of the human and mouse homologues of the Drosophila dachshund gene. Dev Genes Evol 209:537-545

Kozmik Z, Holland ND, Kreslova J, Oliveri D, Schubert M, Jonasova K, Holland LZ, Pestarino M, Benes V, Candiani S (2007) Pax-Six-EyaDach network during amphioxus development: conservation in vitro but context specificity in vivo. Dev Biol 306:143-159

Kulakova M, Bakalenko N, Novikova E, Cook CE, Eliseeva E, Steinmetz PRH, Kostyuchenko RP, Dondua A, Arendt D, Akam M, Andreeva T (2007) Hox gene expression in larval development of the polychaetes Nereis virens and Platynereis dumerilii (Annelida, Lophotrochozoa). Dev Genes Evol 217:39-54

Maddison DR, Maddison WP (2005) MacClade 4: analysis of phylogeny and character evolution, version 4.08. Sinauer, Sunderland

Mallatt J, Giribet G (2006) Further use of nearly complete 28S and 18S rRNA genes to classify Ecdysozoa: 37 more arthropods and a kinorhynch. Mol Phylogenet Evol 40:772-794

Mallatt J, Craig CW, Yoder MJ (2010) Nearly complete rRNA genes assembled from across the metazoan animals: effects of more taxa, a structure-based alignment, and paired-sites evolutionary models on phylogeny reconstruction. Mol Phylogenet Evol 55:1-17

Mardon G, Solomon NM, Rubin GM (1994) dachshund encodes a nuclear protein required for normal eye and leg development in Drosophila. Development 120:3473-3486

Martini SR, Roman G, Meuser S, Mardon G, Davis RL (2000) The retinal determination gene, dachshund, is required for mushroom body cell differentiation. Development 127:2663-2672

Maves L, Schubiger G (1998) A molecular basis for transdetermination in Drosophila imaginal discs: interactions between wingless and decapentaplegic signaling. Development 125:115-124

Minelli A (1998) Molecules, developmental modules, and phenotypes: a combinatorial approach to homology. Mol Phylogenet Evol 9:340-347

Minelli A (2000) Limbs and tail as evolutionarily diverging duplicates of the main body axis. Evol Dev 2:157-165

Mittmann B, Scholtz G (2001) Distal-less expression in embryos of Limulus polyphemus (Chelicerata, Xiphosura) and Lepisma 
saccharina (Insecta, Zygentoma) suggests a role in the development of mechanoreceptors, chemoreceptors, and the CNS. Dev Genes Evol 211:232-243

Nielsen C, Martinez P (2003) Patterns of gene expression: homology or homocracy? Dev Genes Evol 213:149-154

Nissim S, Allard P, Bandyopadhyay A, Harfe BD, Tabin CJ (2007) Characterization of a novel ectodermal signaling center regulating Tbx2 and Shh in the vertebrate limb. Dev Biol 304:9-21

Orrhage L (1993) On the microanatomy of the cephalic nervous system of Nereidae (Polychaeta), with a preliminary discussion of some earlier theories on the segmentation of the polychaete brain. Acta Zool-Stockholm 74:145-172

Orrhage L, Müller MCM (2005) Morphology of the nervous system of Polychaeta (Annelida). Hydrobiologica 535(536):79-111

Panganiban G (2000) Distal-less function during Drosophila appendage and sense organ development. Dev Dyn 218:554-562

Panganiban G, Rubenstein JLR (2002) Developmental functions of the Distal-less/Dlx homeobox genes. Development 129:43714386

Panganiban G, Irvine SM, Lowe C, Roehl H, Corley LS, Sherbon B, Grenier JK, Fallon JF, Kimble J, Walker M, Wray GA, Swalla BJ, Martindale MQ, Carroll SB (1997) The origin and evolution of animal appendages. Proc Natl Acad Sci USA 94:5162-5166

Pappu KS, Mardon G (2004) Genetic control of retinal specification and determination in Drosophila. Int J Dev Biol 48:913-924

Paps J, Baguñà J, Riutort M (2009a) Lophotrochozoa internal phylogeny: new insights from an up-to-date analysis of nuclear ribosomal genes. Proc R Soc B 276:1245-1254

Paps J, Baguñà J, Riutort M (2009b) Bilaterian phylogeny: a broad sampling of 13 nuclear genes provides a new lophotrochozoa phylogeny and supports a paraphyletic basal acoelomorpha. Mol Biol Evol 26:2397-2406

Pflugfelder GO, Roth H, Poeck B, Kerscher S, Schwarz H, Jonschker B, Heisenberg M (1992) The lethal(1)optomotor-blind gene of Drosophila melanogaster is a major organizer of optic lobe development: isolation and characterization of the gene. Proc Natl Acad Sci USA 89:1199-1203

Prpic N-M (2008) Parasegmental appendage allocation in annelids and arthropods and the homology of parapodia and arthropodia. Front Zool 5:17

Prpic N-M, Tautz D (2003) The expression of the proximodistal axis patterning genes Distal-less and dachshund in the appendages of Glomeris marginata (Myriapoda: Diplopoda) suggests a special role of these genes in patterning the head appendages. Dev Biol 260:97-112

Prpic N-M, Janssen R, Wigand B, Klingler M, Damen WGM (2003) Gene expression in spider appendages reveals reversal of exd/hth spatial specificity, altered leg gap gene dynamics, and suggests divergent distal morphogen signaling. Dev Biol 264:119-140

Prpic N-M, Janssen R, Damen WGM, Tautz D (2005) Evolution of dorsal-ventral axis formation in arthropod appendages: H15 and optomotor-blind/bifid-type T-box genes in the millipede Glomeris marginata (Myriapoda: Diplopoda). Evol Dev 7:51-57

Prud'homme B, de Rosa R, Arendt D, Julien J-F, Pajaziti R, Dorresteijn AWC, Adoutte A, Wittbrodt J, Balavoine G (2003) Arthropod-like expression patterns of engrailed and wingless in the annelid Platynereis dumerilii suggest a role in segment formation. Curr Biol 13:1876-1881

Pueyo JI, Couso JP (2005) Parallels between the proximal-distal development of vertebrate and arthropod appendages: homology without an ancestor? Curr Opin Genet Dev 15:439-446

Qiu M, Bulfone A, Martinez S, Meneses JJ, Shimamura K, Pedersen RA, Rubenstein JLR (1995) Null mutation of $D l x$-2 results in abnormal morphogenesis of proximal first and second branchial arch derivatives and abnormal differentiation in the forebrain. Genes Dev 9:2523-2538
Rhode B (1992) Development and differentiation of the eye in Platynereis dumerilii (Annelida, Polychaeta). J Morphol 212:7185

Robledo RF, Rajan L, Li X, Lufkin T (2002) The Dlx5 and Dlx6 homeobox genes are essential for craniofacial, axial and appendicular skeletal development. Genes Dev 16:1089-1101

Ronquist F, Huelsenbeck JP (2003) MRBAYES 3: Bayesian phylogenetic inference under mixed models. Bioinformatics 19:15721574

Saudemont A, Dray N, Hudry B, Le Gouar M, Vervoort M, Balavoine G (2008) Complementary striped expression patterns of $N K$ homeobox genes during segment formation in the annelid Platynereis. Dev Biol 317:430-443

Schmidt-Rhaesa A, Bartolomaeus T, Lemburg C, Ehlers U, Garey JR (1998) The position of the Arthropoda in the phylogenetic system. J Morphol 238:263-285

Scholtz G (2002) The Articulata hypothesis - or what is a segment? Org Divers Evol 2:197-215

Scholtz G (2005) Homology and ontogeny: pattern and process in comparative developmental biology. Theor Biosci 124:121-143

Scholtz G (2010) Deconstructing morphology. Acta Zool-Stockholm 91:44-63

Schoppmeier M, Damen WGM (2001) Double-stranded RNA interference in the spider Cupiennius salei: the role of Distalless is evolutionarily conserved in arthropod appendage formation. Dev Genes Evol 211:76-82

Seaver EC, Kaneshige LM (2006) Expression of ‘segmentation' genes during larval and juvenile development in the polychaetes Capitella sp. I and H. elegans. Dev Biol 289:179-194

Seaver EC, Paulson DA, Irvine SQ, Martindale MQ (2001) The spatial and temporal expression of Ch-en, the engrailed gene in the polychaete Chaetopterus, does not support a role in body axis segmentation. Dev Biol 236:195-209

Sepp KJ, Schulte J, Auld VJ (2001) Peripheral glia direct axon guidance across the CNS/PNS transition zone. Dev Biol 238:4763

Sewell W, Williams T, Cooley J, Terry M, Ho R, Nagy L (2008) Evidence for a novel role for dachshund in patterning the proximal arthropod leg. Dev Genes Evol 218:293-305

Shankland M (2003) Evolution of body axis segmentation in the bilaterian radiation. In: Legakis A, Sfenthourakis S, Polymeni R, Thessalou-Legaki M (eds) The new panorama of animal evolution. Proceedings of the XVIII International Congress of Zoology, September 2000, Athens. Pensoft, Sofia, pp 187-195

Shubin N, Tabin C, Carroll S (1997) Fossils, genes, and the evolution of animal limbs. Nature 388:639-648

Shubin N, Tabin C, Carroll S (2009) Deep homology and the origins of evolutionary novelty. Nature 457:818-823

Smith JE (1957) The nervous anatomy of the body segments of nereid polychaetes. Philos T Roy Soc B 240:135-196

Stock DW, Ellies DL, Zhao Z, Ekker M, Ruddle FH, Weiss KM (1996) The evolution of the vertebrate Dlx gene family. Proc Natl Acad Sci USA 93:10858-10863

Strausfeld NJ, Hansen L, Li Y, Gomez RS, Ito K (1998) Evolution, discovery, and interpretations of arthropod mushroom bodies. Learn Mem 5:11-37

Striedter GF, Northcutt RG (1991) Biological hierarchies and the concept of homology. Brain Behav Evol 38:177-189

Tabin CJ, Carroll SB, Panganiban G (1999) Out on a limb: parallels in vertebrate and invertebrate limb patterning and the origin of appendages. Am Zool 39:650-663

Takaesu NT, Hyman-Walsh C, Ye Y, Wisotzkey RG, Stinchfield MJ, O'Connor MB, Wotton D, Newfeld SJ (2006) dSno facilitates Baboon signaling in the Drosophila brain by switching the affinity of Medea away from Mad and toward dSmad2. Genetics 174:1299-1313 
Telford MJ, Bourlat SJ, Economou A, Papillon D, Rota-Stabelli O (2008) The evolution of the Ecdysozoa. Philos Trans Roy Soc Biol 363:1529-1537

Thompson JD, Gibson TJ, Plewniak F, Jeanmougin F, Higgins DG (1997) The ClustalX Windows interface: flexible strategies for multiple sequence alignment aided by quality analysis tools. Nucleic Acids Res 24:4876-4882

Tomer R, Denes AS, Tessmar-Raible K, Arendt D (2010) Profiling by image registration reveals common origin of annelid mushroom bodies and vertebrate pallium. Cell 142:800-809

Wagner GP (2007) The developmental genetics of homology. Nat Rev Genet 8:473-479

Wallberg A, Curini-Galletti M, Ahmadzadeh A, Jondelius U (2007) Dismissal of Acoelomorpha: Acoela and Nemertodermatida are separate early bilaterian clades. Zool Scr 36:509-523
Westheide W (1997) The direction of evolution within the Polychaeta. J Nat Hist 31:1-15

Williams TA, Nulsen C, Nagy LM (2002) A complex role for Distal-less in crustacean appendage development. Dev Biol 241:302-312

Winchell CJ, Valencia JE, Jacobs DK (2010) Confocal analysis of nervous system architecture in direct-developing juveniles of Neanthes arenaceodentata (Annelida, Nereididae). Front Zool $7: 17$

Wray GA, Abouheif E (1998) When is homology not homology? Curr Opin Genet Dev 8:675-680

Yang X, ZarinKamar N, Bao R, Friedrich M (2009) Probing the Drosophila retinal determination gene network in Tribolium (I): the early retinal genes dachshund, eyes absent and sine oculis. Dev Biol 333:202-214 